\title{
Cyclical Asset Returns in the Consumption and Investment Goods Sector* ${ }^{\dagger}$
}

\author{
Burkhard Heer $^{\mathrm{a}, \mathrm{b}}$, Alfred Maußner ${ }^{\mathrm{c}}$, and Bernd Süssmuth ${ }^{\mathrm{d}, \mathrm{b}}$ \\ a Corresponding author, University of Augsburg, Department of Economics, Universitätsstr. 16, 86159 \\ Augsburg, Germany, burkhard.heer@wiwi.uni-augsburg.de \\ ${ }^{\mathrm{b}}$ CESifo \\ ${ }^{\mathrm{c}}$ University of Augsburg, Department of Economics, Universitätsstr. 16, 86159 Augsburg, Germany, \\ alfred.maussner@wiwi.uni-augsburg.de \\ ${ }^{\mathrm{d}}$ University of Leipzig, Institute for Empirical Research in Economics, Grimmaische Str. 12, 04109 \\ Leipzig, Germany, suessmuth@wifa.uni-leipzig.de
}

This version: July 25, 2017

JEL classification: G12, C63, E22, E32

Key Words: Asset prices, Business Cycles, Equity Premium, Investment Sector, Consumption Sector

\begin{abstract}
We document the empirical fact that asset prices in the consumption-goods and investment-goods sector behave almost identically in the U.S. economy. In order to derive the cyclical behavior of the equity returns in these two sectors, we consider a two-sector real business cycle model with habit formation, sectorspecific growth and adjustment costs of capital. The model is able to replicate the equity premium and the Sharpe values observed empirically, reflects the similarity of the cross-correlation structure between asset returns and aggregate output in the two sectors, and generally succeeds in capturing both the weak predictability of the real risk-free rate and the good predictability of excess returns at the bi-sectoral level.
\end{abstract}

*A preliminary version of the paper was presented at the 11 th INFINITI Conference on International Finance at Aix-en-Provence. Useful comments by Victoria Nuguer and Roselyne Joyeus at this early stage of the paper are appreciated. We thank Dimitris Papanikolaou for providing us with input-output tables, which map industries into investment or consumption producers on the basis of North American Industry Classification Systems (NAICS) codes. We would also like to thank the editor and an anonymous referee for many helpful comments and suggestions. All remaining errors are ours.

${ }^{\dagger}$ Alfred Maußner acknowledges support from the German Science Association (Deutsche Forschungsgemeinschaft) under grant no. MA 1110/3-1 within its priority program "Financial Market Imperfections and Macroeconomic Performance". 


\section{Introduction}

Recent extensions of the standard representative-agent models of a production economy have been successful in matching the equity premium implied by the model with the empirical one. ${ }^{1,2}$ Among others, Boldrin, Christiano and Fisher (2001) propose a two-sector model where labor is immobile between the investment and consumption goods sector for one period after the observation of the shock. In their model, the equity premium results from the variation in the relative price of the two goods. In Uhlig (2007), a sizeable equity premium is generated if real wages are sticky to a considerable degree. Wage stickiness is introduced as in Blanchard and Galí (2007). ${ }^{3}$ Most recently, Albuquerque, Eichenbaum, and Rebelo (2012) introduce preference shocks in the production economy in order to successfully model the weak correlation of stock returns with consumption and output growth.

All these models above only consider the effects of a supply-side or demand-side shock on aggregate stock returns. In the present paper, we explicitly study the dynamics of sectoral asset prices in two production sectors of the economy: a capital goods and consumption goods sector. In Section 2, we first document the empirical regularities that both asset returns and the Sharpe value are moderately higher in the capital goods sector than in the consumption goods sector using data from the U.S. economy from the 1980 s to the end of the 2000s. The same applies to the more narrow period ranging from 1980 to 1999 which excludes equity price crashes due to asset price bubbles. In both cases, the differences are not significantly different from zero at the conventional levels. In addition, the contemporaneous correlation of stock returns with output are found to be insignificant in both sectors.

We construct a new dataset of bi-sectoral price-dividend ratios to assess the predictability of sectoral excess returns and of the risk-free rate. Relying on these data, we confirm the well-documented financial market facts of a good predictability of equity premium series and of a poor predictability of the real risk-free rate also at the sectoral level of consumption goods and capital goods industries. Additionally, we find a substantially

\footnotetext{
${ }^{1}$ In their seminal paper, Mehra and Prescott (1985) estimate an equity premium of 6.18 percent p.a. for the United States over the period 1889-1979.

${ }^{2} \mathrm{~A}$ pioneering work in this area is the production-based asset pricing model of Jerman (1998). Assuming exogenous labor supply, his model has been demonstrated to replicate the empirically observed equity premium successfully. Heer and Maußner (2013) compare the relative performance of one- and two-sector models of production economies with endogenous labor supply with respect to their asset price and labor market implications.

${ }^{3}$ In addition, Uhlig introduces habits in consumption and leisure.
} 
lower variance of the risk-free rate compared to the one of the sector-specific excess returns series.

In Section 3, we propose a two-sector business cycle model that is able to replicate these qualitative findings. The model is an extension of the Boldrin, Christiano and Fisher (2001) model. In particular, we introduce sector-specific adjustment costs of capital allowing us to identify the asset price (Tobin's q) in each sector. In line with Greenwood, Hercowitz, and Krusell (2000) we also consider sector-specific growth of total factor productivity. The essential feature of the model are frictions in the allocation of labor and capital. Without these frictions and with identical technology shocks in both sectors, the model reduces to the standard one-sector model. We thus demonstrate that relatively small departures from the standard model are sufficient to explain our stylized facts on asset returns.

The study most closely related to ours is provided by Ireland and Schuh (2008). They also consider a real business cycle model with two production sectors similar to those in the model of the present paper. Ireland and Schuh identify the sources of changes in total factor productivity in the postwar U.S. economy and show that the main and persistent contributor is the slowdown of the consumption goods sector. In addition, they also introduce a preference shock and find, in accordance with the study of Albuquerque, Eichenbaum, and Rebelo (2012), that this shock helps to reconcile the business cycle properties of the model with the data. However, Ireland and Schuh do not study the asset price implications of their model.

As one of the very few business cycle studies that also considers disaggregate stock market behavior, Covas and Den Haan (2012) analyze an economy with small and large firms that have different access (costs) to bank debt markets. As a consequence, they are able to explain different behavior of these firms with regard to equity issuance, asset prices, and the prices of risk. However, in their model, the required rate of return for investors is specified as an exogenous process while it is endogenous in ours.

The paper is organized as follows. In Section 2, we present the empirical asset price statistics for the investment and consumption goods sector in the U.S. economy during the period 1980-2009. Section 3 introduces our model and Section 4 reports the results from simulations of this model. Section 5 concludes. The interested reader will find the detailed description of the model in the Appendix. 


\section{Empirical facts}

\subsection{Business cycle behavior of sectoral asset returns in the U.S.}

The time series used in this section are of quarterly frequency and refer to the U.S. economy. They cover the period from the first quarter of 1980 to the fourth quarter of 2009. In order to avoid a downward bias due to equity price crashes in the 2000s, we also consider a narrowed period ranging from 1980:Q1 to 1999:Q4 (as well as an extended period ranging from 1973:Q1 to 2002:Q4 in Sections 2.2 and 2.3). Asset price series are drawn from the Datastream Global Equity Indices (GEI) database. The source for the time series to construct an adequate deflator is the U.S. Bureau of Economic Analysis (BEA). The series are individually described as follows.

Asset prices for the consumer goods sector are obtained from an equally weighted average of the breakdown of the Datastream GEI at its Industry Classification Benchmark (ICB) Level 2 "Consumer Goods (CNSMGUS)" and "Consumer Services (CNSMSUS)," respectively. Note that all indices contained in the GEI database are constructed based on a representative sample of stocks covering a minimum 75-80 percent of total market capitalization.

Stock prices for the capital goods sector are drawn from the ICB-2 series "Industrials (INDUSUS)." It comprises the ICB-4 levels: Construction and materials, aerospace and defense, general industrials, electronic and electric equipment, industrial engineering, industrial transportation, and support services. ${ }^{4}$

As our measure of nominal yield on relatively risk-free securities over our period of observation, we rely on the most frequently used Treasury Yield (USGBOND) series adjusted to constant maturity. In order to calculate real returns, we use a consumption deflator series that we obtain by dividing nominal personal consumption expenditures at current prices through real consumption in 2005 dollars (source: BEA). ${ }^{5}$ Real series are constructed by dividing nominal series by this deflator. Annualized returns are

\footnotetext{
${ }^{4}$ Alternatively, the Standard and Poor's 500 Capital Goods index series (SP5GCAP) could have been used. However, in order to avoid introducing some scale bias as, in contrast to our consumption sector ICB series, the S\&P 500 series is based on the market capitalizations of the 500 leading companies only, we decided to use this ICB series for the capital good sector index.

${ }^{5}$ The reason for using a consumption deflator for both sectors instead of, for example, considering the PPI in the case of the capital goods sector series is twofold. First, the consumption deflator is the one used in the seminal studies on the equity premium, i.e. in Mehra and Prescott (1985) and in Kocherlakota (1996), that also contain capital sector stocks in their considered indices. Secondly, it seems straightforward to deflate shares that are ususally held in the same portfolios, though stemming from different sectors, with the same deflator.
} 
calculated in the usual way. Risk or equity premia are calculated as the difference between the real return on the respective sectoral index and the real return on a riskfree security as defined above. Sharpe ratios are the ratios between the equity premium and the standard deviation of the respective asset's returns.

Table 2.1 presents the statistics for the equity premium (in percent) and the Sharpe ratio. The average equity premium in the capital goods sector amounts to 3.91 percent (7.22 percent leaving out the 2000s). The equity premium of the consumption goods sector behaves similarly and amounts to 2.98 (6.95) percent.

\section{Table 2.1}

Equity premium by sector

\begin{tabular}{lcccc}
\hline Index & Mean & Median & Standard deviation & Sharpe ratio \\
\hline 1980:Q1 to 2009:Q4 & & & & \\
Capital goods & 3.91 & 7.50 & 40.81 & 0.093 \\
Consumption goods & 2.98 & 7.55 & 40.13 & 0.072 \\
& $(0.319)$ & & & $(0.879)$ \\
& & & & \\
1980:Q1 to 1999:Q4 & & & 37.10 & 0.189 \\
Capital goods & 7.22 & 8.68 & 41.77 & 0.161 \\
Consumption goods & 6.95 & 15.69 & & $(0.905)$ \\
\hline
\end{tabular}

Notes: Annualized measures based on real returns from the data are calculated as described in the body of the paper. Means, medians, and standard deviations of returns are in percent per annum. Values in parentheses are p-values: In the 'Mean' column they refer to a one-sided test for a positive mean of equity premium difference between capital goods sector index and consumption goods sector index. In the 'Sharpe ratio' column they refer to a two-sided Wald test of a zero difference in the respective Sharpe ratio values. Tests are based on real quarterly series' moments.

Table 2.2 displays the asset return volatility and correlations. The standard deviations of the equity returns in the two sectors coincide and amount to approximately 10 percent. In addition, the correlations of the asset returns with output and consumption are both small in size and statistically insignificant.

Figure 2.1 shows the cross-correlations between stock returns and quarterly lags and leads in real aggregate output for the consumption goods and capital goods sector, respectively. The upper (lower) schedule displays the correlation function values for stock returns of the consumption (investment) goods sector and real GDP as the respective bold line. They are based on correlation coefficients at different quarterly lags and leads such that horizons to the left (right) of the origin represent a respective quarterly 
Table 2.2

Asset return volatility and correlations: 1980:Q1-2009:Q4

\begin{tabular}{lccc}
\hline Index & $\begin{array}{c}\text { Standard } \\
\text { deviation }\end{array}$ & \multicolumn{2}{c}{ Correlations } \\
& & Output & Consumption \\
\hline Capital goods & 9.86 & 0.111 & 0.0584 \\
& & $(0.94)$ & $(0.98)$ \\
Consumption goods & 9.80 & -0.0264 & 0.0136 \\
& & $(0.99)$ & $(0.99)$ \\
\hline
\end{tabular}

Notes: Authors' own calculations based on quarterly returns and growth rates, respectively. Standard deviations of returns are in percent per quarter. HAC consistent p-values in parentheses.

lag (lead) of returns over aggregagte output. Thin lines around the cross-correlation functions show a 90 percent confidence band based on Newey-West standard errors with four lags (Newey and West, 1987).

As noted above, contemporaneus correlations are small in size and statistically insignificant. The respective peak in the cross-correlation function appears at horizon +1 with a significant correlation coefficient at around 0.4, implying that sectoral equity prices lead aggregate output by about a quarter in both sectors. A statistically significant, although less profound, correlation is already given for a 2 to 3 quarters lead of returns. There is also a small and slightly significant negative correlation of about -0.2 for a three quarters lag, though only for the consumption goods sector. ${ }^{6}$ Overall, our figures are quite similar for both sectors and confirm the leads and lags for sectorally aggregated U.S. series reported e.g. in Backus, Routledge, and Zin (2007).

\subsection{Excess return predictability}

Among the 13 central stylized facts about stock market and related time series reported in Campbell (2003) is the well-documented fact that unconditional expected excess returns on U.S. stock over Treasury bills (henceforth, EP for "equity premium") are quite well predictable. To assess this feature, we adopt the strategy proposed in Campbell (2003, Section 4.5). Accordingly, it follows from the log-linearized CAPM that the log price-dividend ratio should embody rational forecasts of dividend growth

\footnotetext{
${ }^{6}$ Note, cross-correlation functions between sectoral returns and real aggregate consumption remain statistically insignificant at all considered horizons, and, for this reason, are not presented.
} 
Figure 2.1: Cross-correlation functions: U.S. sectoral stock returns and aggregate output
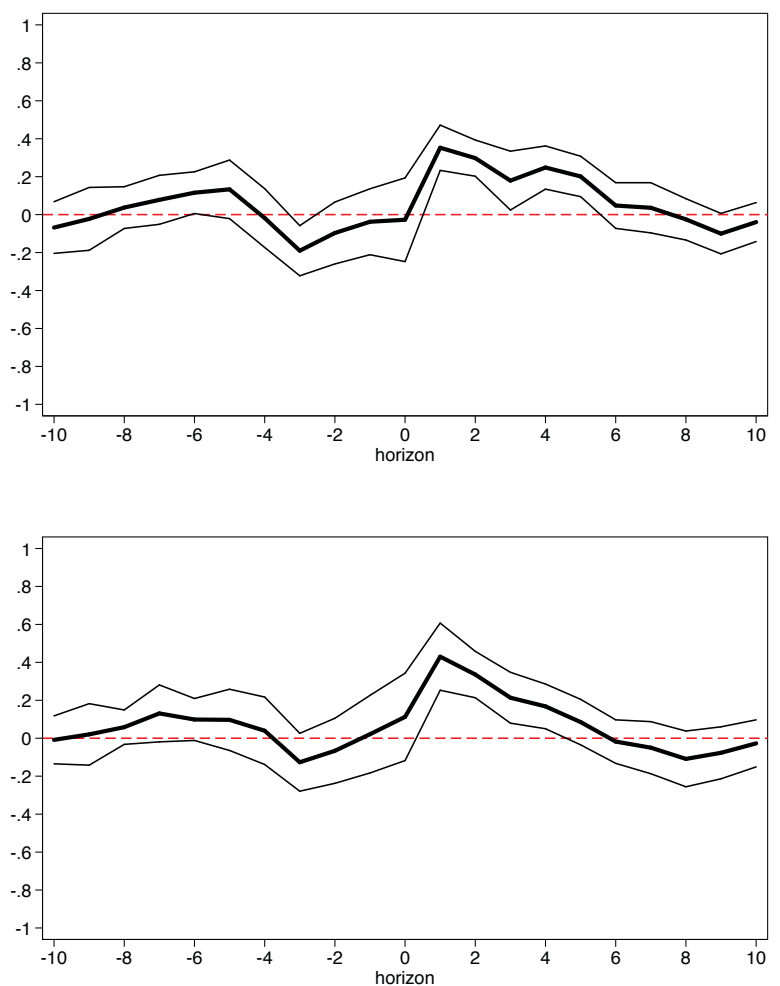

Note: Upper schedule - consumption goods sector, lower schedule - capital goods sector; left to origin returns lag, right to origin - returns lead; thin lines - 90 percent confidence interval (Newey-West standard errors with 4 lags)

rates and stock returns. The empirical relevance of these different forecasts can be assessed by regressing long-horizon excess stock returns series (and long-horizon risk-free rates; see the following section) onto corresponding log price-dividend ratios.

To obtain respective price-dividend ratios at the sectoral level, we use input-output tables from Papanikolaou (2011), which map industries into investment or consumption producers on the basis of North American Industry Classification Systems (NAICS) codes. Unfortunately, although also analyzing bi-sectoral risk premia, volatility measures, and correlation structures of returns with consumption, investment and output growth, Papanikolaou (2011) does not study dividends or price-dividend ratios. Hence, we used the NAICS codes input-output table structure in combination with the (formerly used) Standard Industrial Classification (SIC) scheme to ascribe a sample of 28,469 historical dividends and (unadjusted) closing price series of securities from the NASDAQ list to either the capital goods or consumption goods sector. As our sample would drastically shrink maintaining the hitherto studied period of observation, 
we extend our sample period to the three decades period from 1973:Q1 to 2002:Q4. ${ }^{7}$ Finally, we proceed by computing EP series in natural units over 4, 8 and 16 quarters (1, 2 and 4 years) and regress them onto the respective sectoral log price-dividend ratio divided by its standard deviation. Thus, the regression coefficient (beta) gives the effect of a one standard deviation change in the sectoral log price-dividend ratio on the cumulative rate of return in natural units. The predictability regressions for horizons $k=4,8,16$ are

$$
Y_{t, t+k}^{j}=\alpha_{k}+\beta_{k} \frac{P_{t}^{j}}{D_{t}^{j}}+\varepsilon_{t+k, k} ; \quad Y_{t, t+k}^{j}:=\frac{4}{k} \sum_{i=1}^{k} r_{t+k}
$$

where $r$ denotes either the EP, the equity returns (ER), or the risk-free rate series; $j$ corresponds to either one of the two sectors or the aggregate. For the latter we obtain returns from the quarterly Dow Jones Industrial Average series. Note, in these specifications the error term $\varepsilon_{t+k, k}$ follows an $M A(k-1)$ process under the null of no predictability $\left(\beta_{k}=0\right)$ because of overlapping observations. We avail this feature in our strategy to compute autocorrelation consistent and robust (HAC consistent) standard errors using constrained maximum likelihood (ML) for estimation.

Table 2.3 presents our results on the excess return predictability of equity premia. The capital goods sector log price-dividend ratio forecasts 0.27 percent of the cumulative EP of the capital goods producers at a 1-year (4-quarter) horizon, 0.29 percent at a 2-year (8-quarter), and 0.52 percent at a 4-year (16-quarter) horizon. The consumption goods sector log price-dividend ratio forecasts 0.51 percent of the cumulative EP of the consumption goods producers at a 1-year (4-quarter) horizon, 0.44 percent at a 2-year (8-quarter), and 0.21 percent at a 4 -year (16-quarter) horizon. The first two of these coefficients roughly match the dimension of the beta coefficients for the excess return predictability that we find in the general economy aggregate series. For the corresponding 4-year (16-quarter) horizon the aggregate estimation coefficient is higher. It amounts to 0.37 percent. For the investment goods sector and the aggregate economy corresponding R-squared statistics clearly and monotonously increase over the considered forecasting horizons. Hence, we confirm Campbell's finding that EP series are predictable at the aggregate level. It also seems to apply at the sectoral level. Although, we can confirm this only for the capital goods sector, where at least one beta

\footnotetext{
${ }^{7}$ Due to data limitations regarding information on market capitalization, we construct the dividend ratios using raw trading volumes as weights. Smoothing volumes with an $\operatorname{HP}(1,600)$ filter does not substantially alter the series. For technical reasons concerning the computation of robust (HAC consistent) standard errors and maintaining comparability in the different predictability regressions, we focus on the three decades from 1973 to 2002 and do not extend our sample further to the present.
} 
coefficient estimate turns out statistically significant at a one percent level. Overall higher R-squared statistics increasing with horizon for the aggregate counterpart series confirm the commonly held belief that predictability increases with aggregation in the data.

Table 2.3

Empirical predictability of EPs using log price dividend ratios

\begin{tabular}{|c|c|c|c|c|c|c|}
\hline Horizon & $\begin{array}{c}\text { EP Inv } \\
\text { beta }\end{array}$ & $\mathrm{R}$-squ & $\begin{array}{l}\text { EP Con } \\
\text { beta }\end{array}$ & R-squ & $\begin{array}{c}\text { EP Agg } \\
\text { beta }\end{array}$ & R-squ \\
\hline 4 & $\begin{array}{c}-0.002609 \\
(.003637)\end{array}$ & רחת & $\begin{array}{c}-0.005127 \\
(.004683)\end{array}$ & 0.0354 & $\begin{array}{c}-0.005442^{*} \\
(.002861)\end{array}$ & 0.0559 \\
\hline 8 & $\begin{array}{c}-0.002883 \\
(.002284)\end{array}$ & 0.0009 & $\begin{array}{c}-0.004350 \\
(.003526)\end{array}$ & 0.0220 & $\begin{array}{c}-0.004955^{* *} \\
(.002163)\end{array}$ & 0.0564 \\
\hline 16 & $\begin{array}{c}-0.005173^{* * *} \\
(.001393)\end{array}$ & 0.0215 & $\begin{array}{c}-0.002075 \\
(.002236)\end{array}$ & 0.0986 & $\begin{array}{c}-0.003696^{* *} \\
(.001759)\end{array}$ & 0.1780 \\
\hline
\end{tabular}

Notes: ${ }^{*} p<.10,{ }^{* *} p<.05,{ }^{* * *} p<.01$; standard errors given in parantheses are computed from constrained ML estimations with $M A(k-1)$ error term coefficients constrained to unity. They are consistent with regard to both heteroskedasticity and autocorrelation. R-squared statistics (R-Squ) represent squared correlations between structured part of observations and observed outcomes.

\subsection{Behavior of the risk-free rate and equity returns}

In his comprehensive documentation of stylized facts about the stock market and its relation to short-term interest rates, Campbell (2003) also reports that the real riskfree interest rate (i) has some positive serial correlation and (ii) is not well forecasted by the stock market, since the log price-dividend ratio forecasts less than 1 percent of the variation of the real interest rate at horizons of 1 to 4 years. We confirm feature (i) for the period 1973:Q1 to 2011:Q4, where we calculate the quarterly real risk-free rate $(\mathrm{RFR})$ as

$$
R F R_{t}=\left(1+\frac{R_{t}}{100}\right)^{\frac{1}{4}}-1-\pi_{t}
$$

where $R_{t}$ denotes the annualized bond return and $\pi_{t}$ the quarterly inflation rate, respectively. Its mean is 0.0339 , i.e. about $3.4 \%$ per year, with a standard deviation of 0.0235 , i.e. $2.4 \%$. Its first order autocorrelation in the quarterly series is 0.8 .

In order to confirm stylized fact (ii) also at the level of the consumption goods and capital goods sector, respectively, and later to assess our model's ability to match 
it, we proceed analogously to the preceding section by computing real RFR series in natural units over 4, 8 and 16 quarters (1,2 and 4 years) and regress them onto the respective sectoral log price-dividend ratio divided by its standard deviation. Thus, the corresponding beta again measures the effect of a one standard deviation change in the sectoral log price-dividend ratio on the cumulative growth rate or rate of return in natural units.

Table 2.4 reports the resulting regression coefficients and R-squared statistics. These findings roughly coincide with the second part of stylized fact 12 in Campbell (2003): The real risk-free rate (relative to the EP) is not well forecasted by the stock market, since the log price-dividend ratio forecasts roughly only one tenth or less in case of the RFR compared to the EP-case at horizons of 1 to 4 years. Additionally, the R-squared statistics does neither for the consumption goods sector nor for the aggregate counterpart series continuously increase from a 1-year to a 4-year horizon. An exception is the the capital goods sector, for which the R-squared statistics increases with forecasting horizons. Not a single coefficient is estimated as statistically different from zero.

Table 2.4

Empirical predictability of the real RFR using log price dividend ratios

\begin{tabular}{|c|c|c|c|c|c|c|}
\hline Horizon & $\begin{array}{l}\text { RFR Inv } \\
\text { beta }\end{array}$ & R-squ & $\begin{array}{c}\text { RFR Con } \\
\text { beta }\end{array}$ & R-squ & $\begin{array}{c}\text { RFR Agg } \\
\text { beta }\end{array}$ & R-squ \\
\hline 4 & $-\frac{0.000126}{(.000157)}$ & 0.1203 & $-\frac{0.000204}{(.000184)}$ & 0.2255 & -0.000133 & 0.2262 \\
\hline 8 & $\begin{array}{c}-0.000045 \\
(.000117)\end{array}$ & 0.1230 & -0.000144 & 0.1860 & $\begin{array}{c}-0.000099 \\
(.000138)\end{array}$ & 0.1945 \\
\hline 16 & $\begin{array}{l}0.000006 \\
(.000125)\end{array}$ & 0.1725 & $\begin{array}{c}-0.000049 \\
(.000128)\end{array}$ & 0.1168 & $\begin{array}{c}-0.000010 \\
(.000108)\end{array}$ & 0.1521 \\
\hline
\end{tabular}

Notes: ${ }^{*} p<.10,{ }^{* *} p<.05,{ }^{* * *} p<.01$; standard errors given in parantheses are computed from constrained ML estimations with $M A(k-1)$ error term coefficients constrained to unity. They are consistent with regard to both heteroskedasticity and autocorrelation. R-squared statistics (R-Squ) represent squared correlations between structured part of observations and observed outcomes.

As regards the volatility of the risk-free rate, its standard deviation (variance) for our period of analysis amounts to 0.00537 (0.00003) vis-à-vis a value of 0.0986 (0.0097) for returns in the U.S. capital goods sector and 0.0980 (0.0096) for returns in the U.S. consumption goods sector (Table 2.2). In other words, the variance of stock returns in the two sectors exceeds the variance of the risk-free rate by a factor of about $320 .^{8}$

${ }^{8}$ Allais (2004) reports a corresponding factor of about 60 for the period from 1890 to 1999. 
A flipside of our results - that the excess return is predictable at the sectoral and aggregate level (Table 2.3) but the riskless rate is not (Tabe 2.4) - is that the equity return itself should be predictable using the respective log price dividend ratio. Table 2.5 makes this point. Qualitatively and, approximately also, quantitatively the reported measures match the corresponding ones for the equity premia (Table 2.3).

Table 2.5

Empirical predictability of the real ER using log price dividend ratios

\begin{tabular}{|c|c|c|c|c|c|c|}
\hline Horizon & $\begin{array}{c}\text { ER Inv } \\
\text { beta }\end{array}$ & R-squ & $\begin{array}{c}\text { ER Con } \\
\text { beta }\end{array}$ & $\mathrm{R}$-squ & $\begin{array}{c}\text { ER Agg } \\
\text { beta }\end{array}$ & $\mathrm{R}$-squ \\
\hline 4 & $\begin{array}{c}-0.002736 \\
(.003703)\end{array}$ & 0 & $\begin{array}{c}-0.005331 \\
(.004744)\end{array}$ & 0.0559 & $\begin{array}{c}-0.005572^{*} \\
(.002913)\end{array}$ & 0.0846 \\
\hline 8 & $\begin{array}{c}-0.002928 \\
(.002320)\end{array}$ & 0.0012 & $\begin{array}{c}-0.004494 \\
(.003586)\end{array}$ & 0.0439 & $\begin{array}{c}-0.005053^{* *} \\
(.002210)\end{array}$ & 0.0908 \\
\hline 16 & $\begin{array}{c}-0.005167^{* * *} \\
(.001442)\end{array}$ & 0.0513 & $\begin{array}{c}-0.002116 \\
(.002296)\end{array}$ & 0.1146 & $\begin{array}{c}-0.003706^{* *} \\
(.001805)\end{array}$ & 0.2021 \\
\hline
\end{tabular}

Notes: ${ }^{*} p<.10,{ }^{* *} p<.05,{ }^{* * *} p<.01$; standard errors given in parantheses are computed from constrained ML estimations with $M A(k-1)$ error term coefficients constrained to unity. They are consistent with regard to both heteroskedasticity and autocorrelation. R-squared statistics (R-Squ) represent squared correlations between structured part of observations and observed outcomes.

\section{The model}

We consider an extended version of the two-sector model of Boldrin, Christiano, and Fisher (2001). In particular, we follow Greenwood, Hercowitz, and Krusell (2000) and account for sector specific rates of technological progress and introduce adjustment costs of capital in both sectors.

\subsection{Production}

A consumption good $C$ and an investment good $I$ are produced in two different sectors. The consumption goods sector employs the technology

$$
C_{t}=Z_{C t} N_{C t}^{1-\alpha} K_{C t}^{\alpha}, \quad \alpha \in(0,1)
$$

where $N_{C t}$ and $K_{C t}$ denote labor and capital employed in this sector. $Z_{C t}$ denotes the total factor productivity (TFP). We assume that the log of $Z_{C t}$ follows a random walk 
with drift parameter $a_{C}$ and (possibly) autocorrelated innovations $\epsilon_{C t}$ :

$$
\ln Z_{C t}=\ln Z_{C t-1}+a_{C}+\epsilon_{C t}, \quad \epsilon_{C t}=\rho_{C} \epsilon_{C t-1}+\eta_{C t}, \quad \eta_{C t} \text { iid } \mathcal{N}\left(0, \sigma_{C}\right) .
$$

The investment goods sector (subscript $I$ ) uses the technology so that

$$
I_{t}=Z_{I t} N_{I t}^{1-\alpha} K_{I t}^{\alpha}
$$

is the amount of investment goods which sell at the relative price $p_{t}$. In the long-run this price is driven by different rates of technological progress. The process for total factor productivity in the investment sector is also difference stationary, yet with a different drift rate $a_{I}$ :

$$
\ln Z_{I t}=\ln Z_{I t-1}+a_{I}+\epsilon_{I t}, \quad \epsilon_{I t}=\rho_{I} \epsilon_{I t-1}+\eta_{I t}, \quad \eta_{I t} \text { iid } \mathcal{N}\left(0, \sigma_{I}\right) .
$$

The economy's output at current prices $p_{t}$ is equal to

$$
Y_{t}=C_{t}+p_{t} I_{t}
$$

Total labor and capital in the economy equal

$$
\begin{aligned}
& N_{t}=N_{C t}+N_{I t}, \\
& K_{t}=K_{C t}+K_{I t} .
\end{aligned}
$$

\subsection{Households}

A representative household supplies labor $N_{C t}$ to the consumption goods sector and $N_{I t}$ to the investment goods sector. The respective wage rates are $w_{C t}$ and $w_{I t}$. The household has to choose his labor supply before the shocks $Z_{X t}, X \in\{C, I\}$ to total factor productivity are realized. Besides labor income the household receives dividends $d_{X t}$ per unit of share $S_{X t}$ which he holds of the representative firm in the sector $X$. The current price of shares in units of the consumption good is $v_{X t}$. The household's current period utility function $u$ depends on current consumption, $C_{t}$, a consumption habit $C_{h t}$, and labor $N_{t}$. We choose a function that allows for balanced growth:

$$
u\left(C_{t}, C_{h t}, N_{t}\right)=\ln \left(C_{t}-\chi C_{h t}\right)-\frac{\nu_{0}}{1+\nu_{1}} N_{t}^{1+\nu_{1}}, \quad \chi \geq 0, \nu_{0}, \nu_{1}>0
$$


The consumption habit $C_{h t}$ is internal and equal to past consumption $C_{h t}=C_{t-1}$. Given his initial stocks of shares $S_{C t}$ and $S_{I t}$, the household maximizes his expected intertemporal utility

$$
\mathbb{E}_{t} \sum_{s=0}^{\infty} \beta^{s} u\left(C_{t+s}, C_{h t+s}, N_{t+s}\right), \quad \beta \in(0,1)
$$

subject to his budget constraint:

$$
v_{C t}\left(S_{C t+1}-S_{C t}\right)+v_{I t}\left(S_{I t+1}-S_{I t}\right) \leq w_{C t} N_{C t}+w_{I t} N_{I t}+d_{C t} S_{C t}+d_{I t} S_{I t}-C_{t} .
$$

The first-order conditions are given by

$$
\begin{aligned}
\Lambda_{t} & =\left(C_{t}-\chi C_{t-1}\right)^{-1}-\beta \chi \mathbb{E}_{t}\left(C_{t+1}-\chi C_{t}\right)^{-1} \\
\mathbb{E}_{t} \nu_{0} N_{t+1}^{\nu_{1}} & =\mathbb{E}_{t} \Lambda_{t+1} w_{C t+1} \\
\mathbb{E}_{t} \nu_{0} N_{t+1}^{\nu_{1}} & =\mathbb{E}_{t} \Lambda_{t+1} w_{I t+1} \\
1 & =\beta \mathbb{E}_{t} \frac{\Lambda_{t+1}}{\Lambda_{t}} \frac{d_{C t+1}+v_{C t+1}}{v_{C t}} \\
1 & =\beta \mathbb{E}_{t} \frac{\Lambda_{t+1}}{\Lambda_{t}} \frac{d_{I t+1}+v_{I t+1}}{v_{I t}}
\end{aligned}
$$

where $\Lambda_{t}$ is the multiplier of the budget constraint (3.9). Equations (3.10d) and (3.10e) determine the household's portfolio allocation.

\subsection{Firms}

The representative firm in the consumption sector maximizes

$$
V_{C t}=\mathbb{E}_{t} \sum_{s=0}^{\infty} \beta^{s} \frac{\Lambda_{t+s}}{\Lambda_{t}}\left[C_{t+s}-w_{C t+s} N_{C t+s}-p_{t+s} I_{C t+s}\right]
$$

subject to (3.1) and

$$
K_{C t+1}=\Phi_{C}\left(I_{C t} / K_{C t}\right) K_{C t}+(1-\delta) K_{C t}, \quad \delta \in(0,1]
$$

where $\delta$ denotes the rate of capital depreciation. The function $\Phi_{C}$ captures adjustment costs of capital. The first-order conditions for the optimal choice of $N_{C t}, I_{C t}$ and $K_{C t+1}$ 
are:

$$
\begin{aligned}
w_{C t} & =(1-\alpha) \frac{C_{t}}{N_{C t}} \\
q_{C t} & =\frac{p_{t}}{\Phi_{C}^{\prime}\left(I_{C t} / K_{C t}\right)} \\
q_{C t} & =\beta \mathbb{E}_{t} \frac{\Lambda_{t+1}}{\Lambda_{t}}\left\{\alpha \frac{C_{t+1}}{K_{C t+1}}-\frac{p_{t+1} I_{C t+1}}{K_{C t+1}}+q_{C t+1}\left[\Phi_{C}\left(I_{C t+1} / K_{C t+1}\right)+1-\delta\right]\right\}
\end{aligned}
$$

where $q_{C t}$ (Tobin's $q$ ) is the Lagrange multiplier on the equation governing capital accumulation. In addition, the transversality condition

$$
\lim _{s \rightarrow \infty} \mathbb{E}_{t} \beta^{s} \Lambda_{t+s} q_{C t+s} K_{C t+s+1}=0
$$

must hold. In this case, one can show (see Heer and Maußner (2009), p. 317) that $V_{C t+1}=q_{C t} K_{C t+1}$.

Analogously, the representative firm in the investment goods sector maximizes

$$
V_{I t}=\mathbb{E}_{t} \sum_{s=0}^{\infty} \beta^{s} \frac{\Lambda_{t+s}}{\Lambda_{t}}\left[p_{t+s} I_{t+s}-w_{I t+s} N_{I t+s}-p_{t+s} I_{I t+s}\right]
$$

subject to (3.3) and

$$
K_{I t+1}=\Phi_{I}\left(I_{I t} / K_{I t}\right) K_{I t}+(1-\delta) K_{I t}, \quad \delta \in(0,1] .
$$

The respective first-order conditions are:

$$
\begin{aligned}
w_{I t} & =(1-\alpha) p_{t} \frac{I_{t}}{N_{I t}}, \\
q_{I t} & =\frac{p_{t}}{\Phi_{I}^{\prime}\left(I_{I t} / K_{I t}\right)}, \\
q_{I t} & =\beta \mathbb{E}_{t} \frac{\Lambda_{t+1}}{\Lambda_{t}}\left\{p_{t+1} \alpha \frac{I_{t+1}}{K_{I t+1}}-\frac{p_{t+1} I_{I t+1}}{K_{I t+1}}+q_{I t+1}\left[\Phi_{I}\left(I_{I t+1} / K_{I t+1}\right)+1-\delta\right]\right\},
\end{aligned}
$$

and the transversality condition is

$$
\lim _{s \rightarrow \infty} \mathbb{E}_{t} \beta^{s} \Lambda_{t+s} q_{I t+s} K_{I t+s+1}=0
$$

We parameterize the capital adjustment cost functions $\Phi_{X}, X \in\{C, I\}$ as in Jermann 
(1998):

$$
\Phi_{X}\left(I_{t} / K_{t}\right):=\frac{a_{1 X}}{1-\zeta_{X}}\left(\frac{I_{t}}{K_{t}}\right)^{1-\zeta_{X}}+a_{2 X}, \quad \zeta_{X}>0
$$

The parameters $a_{i X}, i=1,2$ are functions of $a_{X}, \alpha$, and $\delta$, which follow from our assumption that investment on the balanced growth path is costless. ${ }^{9}$

Firms from both sectors transfer their profits less retained earnings as dividends to the household sector and finance the remaining part of their investment expenditures from issuing new equity:

$$
\begin{aligned}
d_{X t} S_{X t} & =Y_{X t}-w_{X t} N_{X t}-R E_{X t}, \quad Y_{X t} \in\left\{C_{t}, p_{t} I_{t}\right\} \\
v_{X t}\left(S_{X t+1}-S_{X t}\right) & =p_{t} I_{X t}-R E_{X t} .
\end{aligned}
$$

Thus, in equilibrium, the budget constraint of the household implies the definition of GDP given in equation (3.5).

\subsection{Stationary equilibrium and calibration}

The equations characterizing the stationary equilibrium are summarized in the Appendix. Table 3.1 presents our benchmark calibration. We distinguish three sets of parameters. For the first set, $\left\{\alpha, \delta, \nu_{1}, a_{X}, \rho_{X}, \sigma_{X}\right\}$, we use direct observations from the U.S. economy. For the second set, $\left\{\beta, \nu_{0}\right\}$, we use the equilibrium conditions on the balanced growth path. The final set, $\left\{\chi, \zeta_{X}\right\}$, comprises parameters which are not directly observable. For their choice we either employ values found in the literature or choose them to optimize the match of the model statistics with the following empirical observations presented in Table 2.1:

1. Annualized equity premia of 2.98 and 3.91 percentage points in the consumption and investment goods sectors.

2. Sharpe ratios of 0.072 and 0.093 .

3. Zero correlations between the equity returns and quarterly output growth.

Our estimates of the parameters of the processes (3.2) and (3.4) employ a data set provided by Fernald (2014). Since our model excludes factor hoarding, we use the

\footnotetext{
${ }^{9}$ See the Appendix for details.
} 
Table 3.1

Calibration of the model

\begin{tabular}{|c|c|c|}
\hline Parameter & Value & Description \\
\hline \multicolumn{3}{|r|}{ Preferences } \\
\hline$\beta$ & 0.0994 & Discount factor \\
\hline$\chi$ & 0.075 & Habit parameter \\
\hline$N$ & 0.33 & Stationary fraction of hours worked \\
\hline$\nu_{1}$ & 3.33 & Inverse of Frisch elasticity of labor supply \\
\hline \multicolumn{3}{|r|}{ Production } \\
\hline$\alpha$ & 0.36 & Capital share \\
\hline$\delta$ & 0.021 & Depreciation rate \\
\hline$\zeta_{C}$ & 6.0 & $\begin{array}{l}\text { Elasticity of investment to capital ratio wrt } \\
\text { Tobin's q in consumption goods sector }\end{array}$ \\
\hline$\zeta_{I}$ & 2.0 & $\begin{array}{l}\text { Elasticity of investment to capital ratio wrt } \\
\text { Tobin's q in investment goods sector }\end{array}$ \\
\hline$a_{C}$ & 0.00054 & $\begin{array}{l}\text { Average quarterly TFP growth rate in } \\
\text { consumption goods sector }\end{array}$ \\
\hline$a_{I}$ & 0.0077 & $\begin{array}{l}\text { Average quarterly TFP growth rate in investment } \\
\text { goods sector }\end{array}$ \\
\hline$\varrho_{C}$ & 0.0 & $\begin{array}{l}\text { Autocorrelation of TFP shock in consumption } \\
\text { goods sector }\end{array}$ \\
\hline$\varrho_{I}$ & 0.28 & $\begin{array}{l}\text { Autocorrelation of TFP shock in investment } \\
\text { goods sector }\end{array}$ \\
\hline$\sigma_{C}$ & 0.0070 & $\begin{array}{l}\text { Standard deviation of TFP shock innovations in } \\
\text { consumption goods sector }\end{array}$ \\
\hline$\sigma_{I}$ & 0.0084 & $\begin{array}{l}\text { Standard deviation of TFP shock innovations in } \\
\text { investment goods sector }\end{array}$ \\
\hline
\end{tabular}

unadjusted growth rates of total factor productivity presented in columns $\mathrm{Q}$ and $\mathrm{R}$ of his data sheet. Our estimates over the period 1980:Q1-2010:Q4 reveal no significant autocorrelation in the process for $\epsilon_{C t}$. Therefore, we set $\rho_{C}=0$. Table 3.1 presents our estimates for $a_{X}, \sigma_{X}$, and $\rho_{I}$. They reveal that growth in the investment goods industry is significantly larger and more volatile than in the consumption goods sector. In particular, the drift rate is about 14 times larger and the standard deviation of the innovations about 20 percent higher.

Our value of $\alpha=0.36$ reflects the share of capital income and has been employed in numerous studies on the U.S. economy. As Boldrin, Christiano, and Fisher (2001) we 
set $\delta=0.021$ in both sectors. Our value of $\nu_{1}=3.33$ implies a Frisch elasticity of labor supply equal to 0.30 . In addition, we specify $\nu_{0}$ so that $N=0.33$. Our choice of $\beta=0.994$ implies an annual risk-free rate of 4.19 percent while the average real annual return of U.S. treasury bills found in our data set is 3.4 percent for the extended period (1973:Q1-2011:Q4, see Section 2.3) and 4.29 percent for the shorter period (1980:Q12009:Q4, see Section 2.1). Jermann (1998) estimates the habit persistence parameter $\chi=0.82$ from matching empirical moments to those implied by his model. Christiano, Eichenbaum and Evans (2005) estimate $\chi=0.65$ from their medium scale model. We choose an intermediate value of $\chi=0.75$. Our values of $\zeta_{C}=6$ and $\zeta_{I}=2$ were found by minimizing the squared relative distance between the six targets from Table 2.1 and the respective statistics implied from simulations of our model over a coarse grid over $[2,7] \times[2,7]$. We also examined the sensitivity of our results against a simulation which employs $\zeta_{C}=\zeta_{I}=1 / 0.23$, the value estimated by Jermann (1998). Our benchmark calibration slightly outperforms this version. ${ }^{10}$

\subsection{Computation of the equity premium}

Heer and Maußner (2009) demonstrate that the real one-period gross rate of return $R_{X t+1}=\left(v_{X t+1}+d_{X t+1}\right) / v_{X t}$ with $X \in\{C, I\}$ is independent of the firm's dividend policy and equals

$$
\begin{aligned}
R_{C t+1} & =\frac{C_{t+1}-w_{C t+1} N_{C t+1}-p_{t+1} I_{C t+1}+q_{C t+1} K_{C t+2}}{q_{C t} K_{C t+1}} \\
R_{I t+1} & =\frac{p_{t+1} I_{t+1}-w_{I t+1} N_{I t+1}-p_{t+1} I_{I t+1}+q_{I t+1} K_{I t+2}}{q_{I t} K_{I t+1}}
\end{aligned}
$$

in the consumption goods and the investment goods sector, respectively.

The risk-free rate of return is given by

$$
r_{t}=\frac{\Lambda_{t}}{\beta \mathbb{E}_{t} \Lambda_{t+1}}
$$

In order to compute the policy functions of the model, we use perturbation methods with a third-order approximation. We combine Fortran code (for speed) with the abilities of Matlab's symbolic toolbox (for accurate first-, second-, and third-order derivatives). As is known from Andreasen (2012), third-order approximations are re-

\footnotetext{
${ }^{10}$ The minimum of our distance measure is 0.7568 while the simulation with Jermann's parameter yields 0.7783 .
} 
quired to capture time-varying effects of the amount of uncertainty embedded in the driving processes (3.2) and (3.4). In the present model, however, these effects are almost negligible. In order to compute the risk-free rate from (3.19), we compute the conditional expectation in the numerator via Gaus-Hermite integration with six points in each of the two dimensions.

\section{Results}

\subsection{Impulse responses}

Figure 4.1 displays the responses of the model to a shock to the growth rate of total factor productivity (tfp) in the consumption goods sector. The shock occurs in period two. The innovations of the process in (3.2) are not autocorrelated so that the growth rate returns to its long-run level in period three. The responses of the variables are percentage deviations from the paths they would have followed without the shock. Therefore, any persistent deviation from zero indicates a permanent shift of the growth path caused by the shock.

Figure 4.1: Impulse responses to a shock in the consumption sector
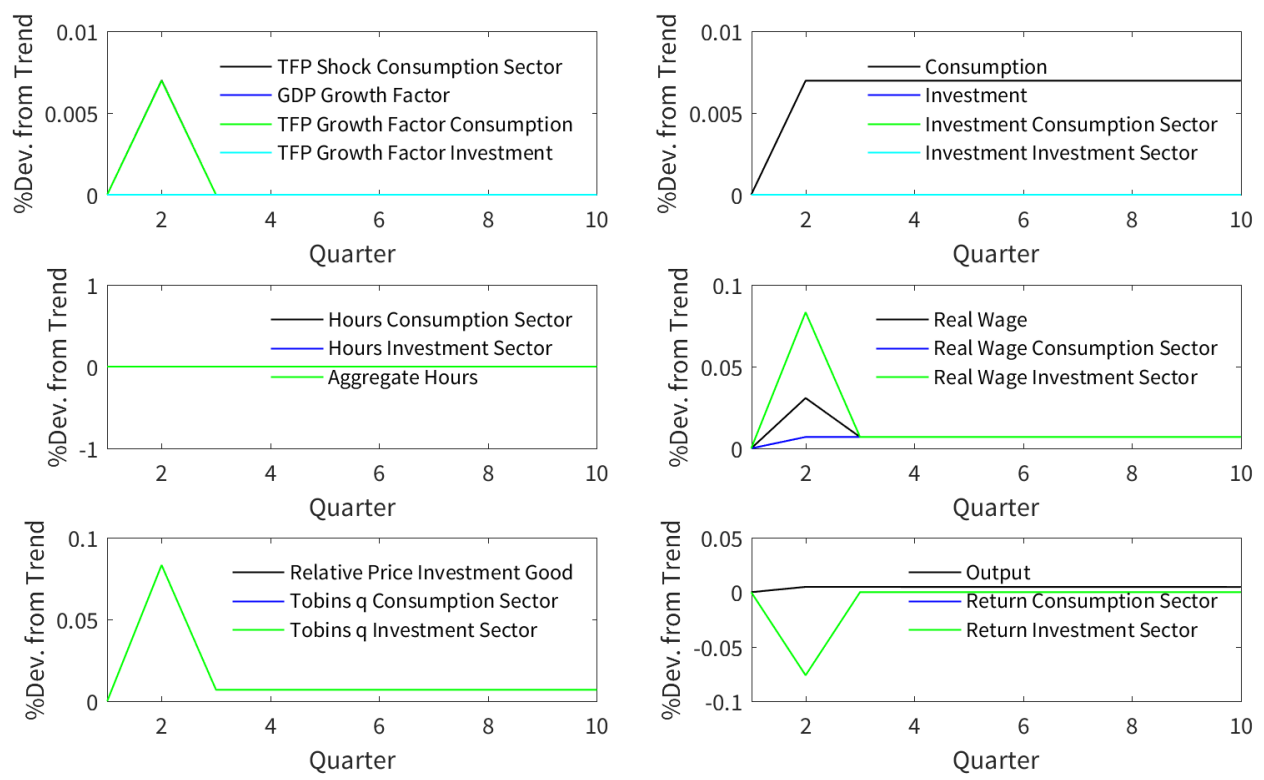

The upper left panel of Figure 4.1 indicates that the shock triggers a one-time increase of the growth factor of total factor productivity in the consumption sector and an 
according shift in the growth factor of aggregate output in current prices. ${ }^{11}$ Since both factors of production are fixed in supply within the period, the shock displaces the time path for consumption one-to-one. Investment stays on its growth path so that output in fixed prices increases by less than consumption. The middle left panel shows that hours do not react to the shock. Wages in the consumption goods sector soak up the entire productivity increase. The household anticipates that wages will be back on the growth path in the next quarter and has no incentive to change his future supply of hours. Given the unchanged path of sectoral production, the relative price of investment goods increases to prevent the household from increasing his savings. Tobin's q mimics this price effect one-to-one in both sectors (see the lower left panel of the figure). The lower right panel plots the return to one unit of foregone consumption in quarter $t$ which materializes in the next quarter $t+1$. In the period after the shock scaled prices and quantities are back to their pre-shock values. The drop of the expost returns displayed in Figure 4.1, therefore, merely reflects the one-time increase of scaled share prices. Finally, since output in constant prices follows its shifted trend path after period two, its growth rate in quarter two must be smaller than in quarter one. Hence, the sectoral returns must correlate positively with output growth.

Figure 4.2 displays the response of the economy to a tfp-schock in the investment goods sector. This shock is autocorrelated (see the upper left panel of the figure) so that anticipated price changes trigger additional effects.

Again, the factors of production cannot react to the shock in quarter one. Therefore, the real wage in the consumption sector cannot change before quarter two, and only the growth path of investment shifts outward in the period of the shock. The price of investment goods must fall so that the household is willing to buy the additional goods without changing the path of consumption. Accordingly, the real wages paid to workers in the investment goods sector drop immediately and the household also expects lower wages in the future. He starts to reallocate hours from the investment to the consumption goods sector so that expected real wages will be equal across both sectors. As the middle left panel of the figure shows, this will be achieved at a lower level of aggregate hours. In both sectors, investment increases relative to the existing stock of capital and boosts Tobin's q. In the investment goods sector, the lower price of investment goods reverses this effect so that q actually falls (see the lower left panel of Figure 4.2). In the consumption goods sector it mitigates the increase of Tobin's q.

\footnotetext{
${ }^{11}$ We show in the Appendix that aggregate output in current prices, $Y_{t}=C_{t}+p_{t} I_{t}$ grows at the rate $z_{t}-1=z_{C t} z_{I t}^{1 /(1-\alpha)}-1 . z_{C t}$ and $z_{I t}$ are the growth factor of tfp in the consumption and the investment goods sector, respectively.
} 
Figure 4.2: Impulse responses to a shock in the investment sector
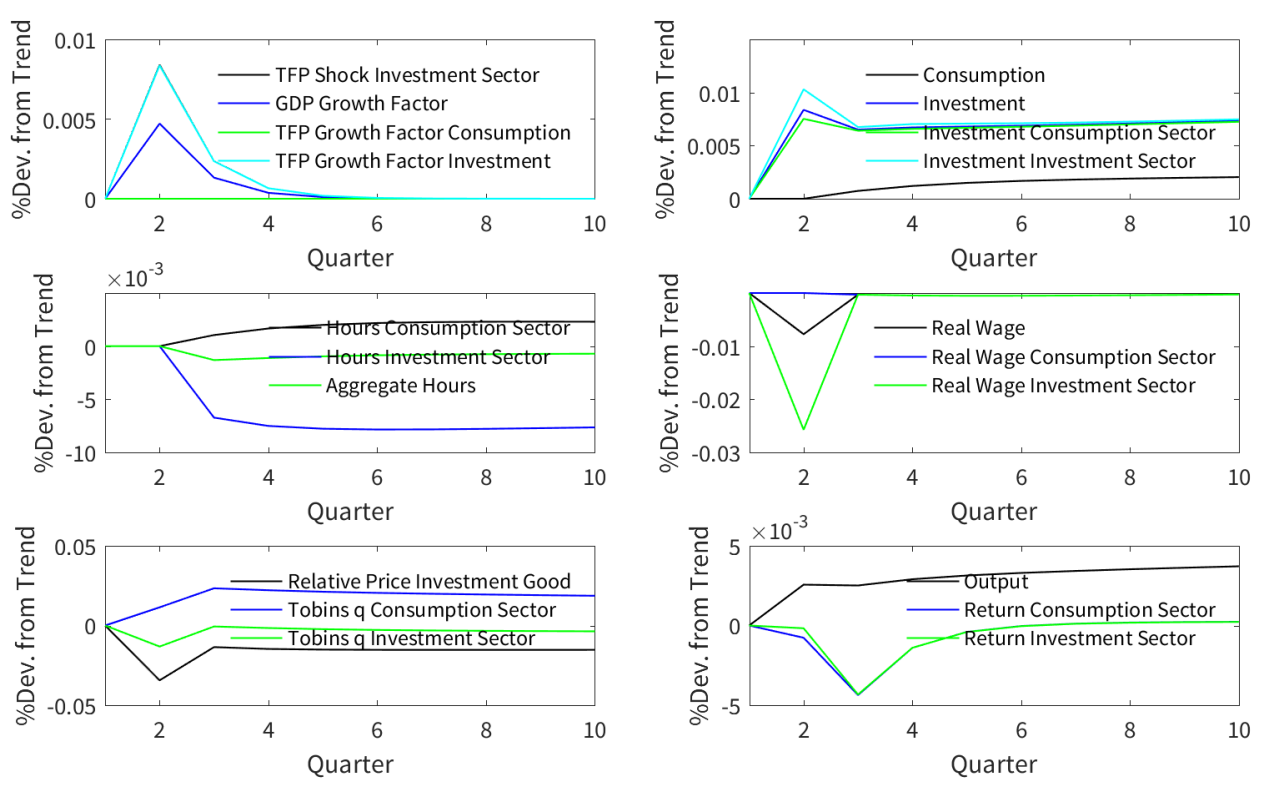

The different development of share prices also explains the stronger fall of the return to equity in the consumption sector in the first two quarters after the shock displayed in the lower right panel of Figure 4.2. Besides the development of share prices, the response of the rates of return reflects several, partly opposing effects (see the nominator in equations (3.18)). In the investment sector, lower goods prices and increased outlays for new equipment dominate the effects of higher output and a lower payroll and drive down the return to equity. In the consumption goods sector increased spending on new equipment and a higher payroll dominate the effect of increased production. As in the case of the consumption sector tfp-shock, the growth of output in quarter two is smaller than in quarter one so that both shocks induce a positive correlation between the growth rate of aggregate output and the sectoral equity returns.

\subsection{Business cycle statistics}

Table 4.1 presents summary statistics, which document both the business cycle properties of the model and its ability to account for the observed equity premia and Sharpe ratios. The business cycle statistics were computed as averages over 500 simulations of the model. Each simulated time series consists of 128 quarters. Since our solution yields policy functions for scaled variables, we used the simulated time series for the growth factors to transform back to level variables. Second moments were then computed from HP-filtered levels. The filter weight was $\lambda=1,600$. The empirical 
moments reported in the table are taken from Cooley and Prescott (1995), Table 1.1. The asset price statistics are each averages from one long simulated time series with $1,000,000$ observations so that we can be confident for a law of large numbers to apply.

Table 4.1

Business cycle and return statistics

\begin{tabular}{|c|c|c|c|c|c|c|c|}
\hline \multirow{3}{*}{$\begin{array}{l}\text { Statistic } \\
S_{Y}\end{array}$} & \multirow{3}{*}{$\begin{array}{c}\text { Data } \\
1.72\end{array}$} & \multicolumn{6}{|c|}{ Model } \\
\hline & & \multirow{2}{*}{$\frac{\mathrm{BM}}{0.71}$} & \multirow{2}{*}{$\begin{array}{c}\nu_{1}=0 \\
0.67\end{array}$} & \multirow{2}{*}{$\frac{\mathrm{NAC}}{0.78}$} & \multirow{2}{*}{$\frac{\mathrm{ML}}{0.61}$} & \multicolumn{2}{|c|}{$\mathrm{BCF}$} \\
\hline & & & & & & 1.97 & 1.97 \\
\hline$S_{C} / S_{Y}$ & 0.74 & 1.26 & 1.31 & 1.16 & 1.17 & 0.67 & 0.69 \\
\hline$S_{I} / S_{Y}$ & 2.97 & 1.25 & 1.23 & 2.47 & 1.28 & 1.67 & 1.67 \\
\hline$S_{N} / S_{Y}$ & 0.98 & 0.20 & 0.51 & 0.15 & 0.56 & 0.52 & 0.51 \\
\hline$r_{Y C}$ & 0.83 & 0.92 & 0.92 & 0.66 & 0.92 & 0.95 & 0.95 \\
\hline$r_{Y I}$ & 0.79 & 0.45 & 0.38 & 0.58 & 0.62 & 0.97 & 0.97 \\
\hline$r_{Y N}$ & 0.92 & -0.32 & -0.18 & 0.52 & -0.46 & 0.86 & 0.86 \\
\hline$E P_{C}$ & 2.98 & 3.00 & 3.03 & 3.03 & 0.17 & 6.45 & . \\
\hline$E P_{I}$ & 3.91 & 3.24 & 3.17 & 3.16 & 0.16 & 6.62 & . \\
\hline$E P_{E}$ & & 3.07 & 3.12 & 3.09 & 0.17 & 6.51 & 6.63 \\
\hline$S R_{C}$ & 0.072 & 0.059 & 0.060 & 0.061 & 0.014 & 0.087 & . \\
\hline$S R_{I}$ & 0.093 & 0.062 & 0.062 & 0.062 & 0.018 & 0.088 & . \\
\hline$S R_{E}$ & & 0.061 & 0.061 & 0.061 & 0.016 & 0.087 & 0.36 \\
\hline$r_{r_{c} g_{y}}$ & -0.03 & 0.66 & 0.68 & 0.59 & 0.81 & 0.59 & . \\
\hline$r_{r_{I} g_{y}}$ & 0.11 & 0.57 & 0.61 & 0.60 & 0.59 & 0.60 & . \\
\hline
\end{tabular}

Notes: $S_{x}$ denotes the standard deviation of variable $x ; r_{x y}$ denotes the correlation between $x$ and $y$ at zero lag. $r_{r_{X} g_{y}}$ is the contemporaneous correlation between the return on equity in sector $X$ and the growth rate of real gdp. The column BM presents the results from the benchmark calibration, the column $\nu_{1}=0$ is the Hansen (1985) indivisible labor specification, the column NAC presents the results for neglecting adjustment costs, the column ML assumes sectoral mobile labor. The two rightmost columns under the heading BCF refers to simulations of the model of Boldrin et al. (2001). The left column presents our analysis of this model while the right column gives the results from their paper. Data not available in this paper are marked with a dot.

Columns 3 through 7 in Table 4.1 report results from various versions of our business cycle model. In column 3, labeled BM, we present the results for the benchmark calibration. Next, we consider the case with indivisible label following Hansen (1985) by setting $\nu_{1}=0$. Column NAC presents the results for negligible adjustment costs, while those in column ML assume sectoral mobile labor within each period. The statistics in the two columns under the heading BCF display summary statistics from the two-sector model of Boldrin, Christiano, and Fisher (2001) (henceforth BCF). The left column presents the results from our solution and simulation of this model while the right column displays the results from their paper.

The main difference between our model and the BCF model are adjustment costs and different driving forces for sectoral TFP levels. The BCF economy is driven by 
a single shock to the growth factor of labor augmenting technical progress and there are no adjustment costs of capital accumulation. BCF use a projection method to solve their model while we rely on a third-order perturbation method. Despite this methodological difference we are able to reproduce their results almost perfectly, except for their value of the Sharpe ratio. The BCF model implies a standard deviation of output which is much higher than the one in our model. Comparing the entries in the columns labeled BM and NAC confims that adjustment costs of capital explain part of this difference. The much larger part of the difference can be traced to the standard deviation of the driving process. The standard deviation of the innovations in their random walk for labor augmenting technical progress is set equal to 0.018 and, thus, amounts to more than twice the standard deviation of the innovations of the TFP shock in the investment goods sector of our model. The absence of adjustment costs in the BCF model removes the negative correlation between hours and output implied by our model. The respective entry in the NAC column confirms this result. However, the single driving process and its greater volatility imply a much higher equity premia for the economy and sectoral equity premia much closer to each other than in our model, which, in turn, is much closer to the data.

Moreover, different adjustment costs of capital in the two sectors increase the spread between the sectoral equity premia towards those observed in our data set, yet they also reduce the volatility of output and the relative volatility of investment. This can be seen from the respective entries in the columns BM and NAC.

All versions of our model underpredict the volatility of hours and the cross-correlation between hours and output. Column $\nu_{1}=0$ reveals that both results are driven by our assumption on the Frisch elasticity of labor supply. In the indivisible labor version of the model (with an infinite Frisch labor supply elasticity) the volatility of hours doubles and the negative correlation with output is cut in half.

Finally, column ML gives a clue as to what drives the equity premia and Sharpe ratios in our model. It presents the statistics from a version of the model where we assume that labor is not pre-allocated but can freely move between the two sectors after the shocks have been observed. Labor mobility increases the volatility of hours and reduces the volatility of wages. The latter effect is much more pronounced than the former. As a result, the volatility of asset returns decreases by a factor of about four and the equity premia become negligible.

Figure 4.3 displays the quarterly growth rate of business output from Fernald (2014) and the rate predicted by our model, if we use the residuals from the estimated processes 
(3.2) and (3.4) as the model's driving forces. The model tracks the data quite well. The correlation coefficient between both series is 0.74 .

Figure 4.3: Real business output: actual versus predicted growth rate

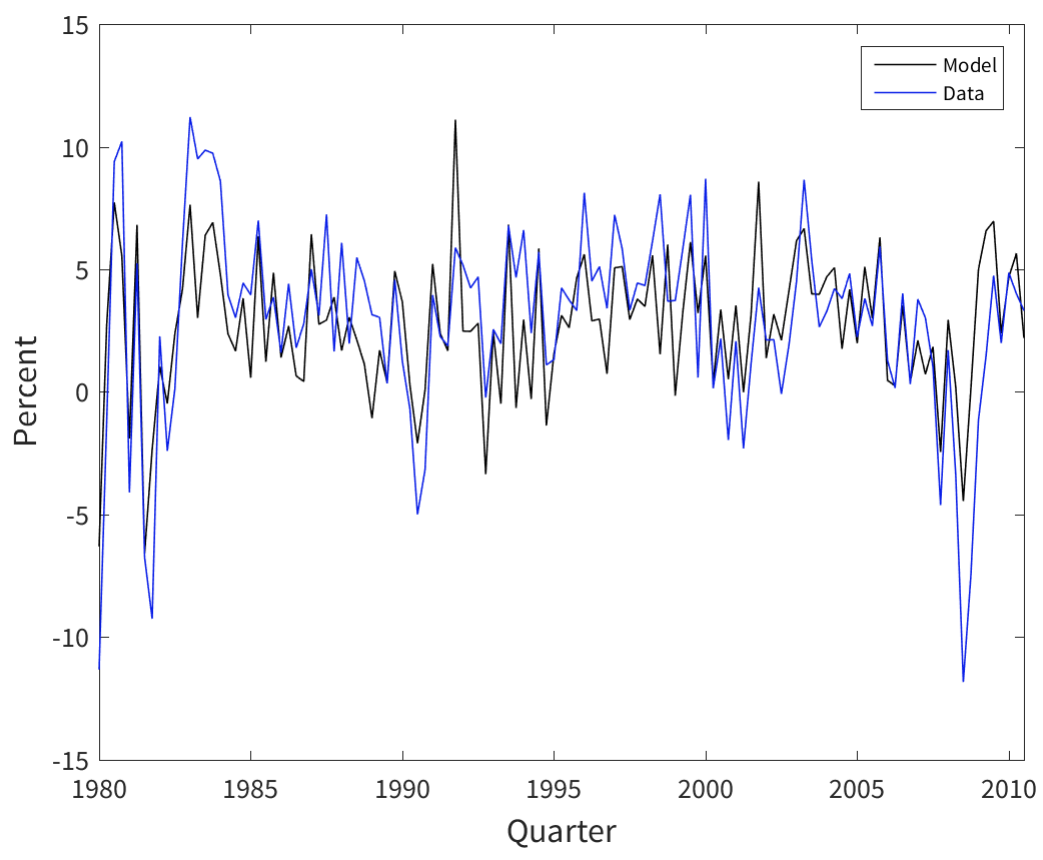

\subsection{Asset price statistics}

Table 4.1 presents in rows 8 through 15 the asset price statistics of our various simulation studies. The entries in the columns labelled data and BM document that our model correctly predicts the equity premium in the consumption sector and under estimates the equity premium in the investment sector. The standard deviations estimated from the simulation are 3.1 and 3.3 percentage points, respectively. Thus the model is in line with data that the equity premia in the investment goods sector is not significantly higher than in the consumption goods sector. The Sharpe ratios implied by the model are smaller than those in the data and reflect the fact that both returns are slightly more volatile in our simulations than they are in the data. Note that we obtain this result without introducing leverage into our model. All versions of the model, including the $\mathrm{BCF}$ model, however, overpredict the correlations of the sectoral equity premia with the rate of output growth, as was to be anticipated from Figures 4.1 and $4.2 .^{12}$

\footnotetext{
${ }^{12}$ In a previous version of the model with identical drift rates reported in Heer, Maußner, and
} 
Figure 4.4: Cross-correlations: simulated sectoral stock returns and aggregate output
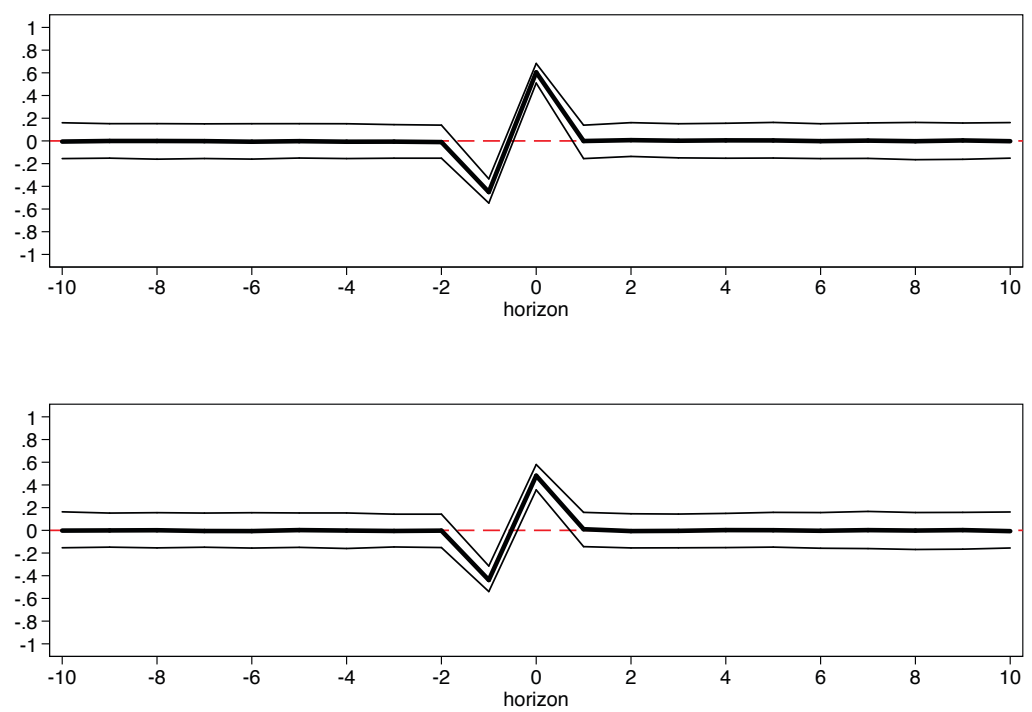

Note: Median (bold) and 5th/95th percentile (thin) from 1,000 episodes with 128 returns each; upper schedule - consumption goods sector, lower schedule - capital goods sector; left to origin - returns lag, right to origin - returns lead

To assess the cross-correlation structure generated by the model in more detail, we seek to replicate Figure 2.1. From 138,000 simulated pseudo-quarterly data of sectoral returns and aggregate output, we discarded the first 10,000 observations as burn-in phase and divided the remaining data into 1,000 episodes with 128 observations (similar to our sample period size in Section 2). In analogy to Figure 2.1, Figure 4.4 shows median cross-correlation function values for different lag/lead horizons (bold lines) as well as the 5th and 95th percentile of correlations across all 1,000 runs for each lag/lead (thin lines). Overall, the lead lag cross-correlation structure seems somewhat "compressed" compared to the empirical one shown in Figure 2.1. Its peak is found for both sectors at a zero-lag with a significant correlation coefficient at around 0.5. There is no significant correlation discernibly different from zero at any quarterly leads of returns. However, a negative correlation of about -0.5 is generated at a lag of one quarter for both sectors. It clearly outweighs, in terms of size, the one found in the actual series at a three quarters lag for the consumption goods sector.

\subsection{Excess return predictability in the model}

Süssmuth (2013), we found correlations close to zero if we assumed that the innovations in the investment sector were about four times more volatile than in the consumption sector. 
In Section 2, we found that the capital goods sector log price-dividend ratio forecasts 0.27 percent of the variance of the EP of the capital goods producers at a 1-year horizon, 0.29 percent at a 2 -year, and 0.52 percent at a 4 -year horizon, respectively. Whilst, the consumption goods sector log price-dividend ratio forecasts 0.51 percent of the variance of the EP of the consumption goods producers at a 1-year horizon, 0.44 percent at a 2-year, and 0.21 percent at a 4-year horizon, repectively. Corresponding R-squared statistics clearly and continuously increase over the considered forecasting horizons for the capital goods sector and the industrial average. In the following, regressions are run in analogy to the analysis of the empirical series in Section 2.2.

Figure 4.5: Predicting EPs by log price dividend ratios: model
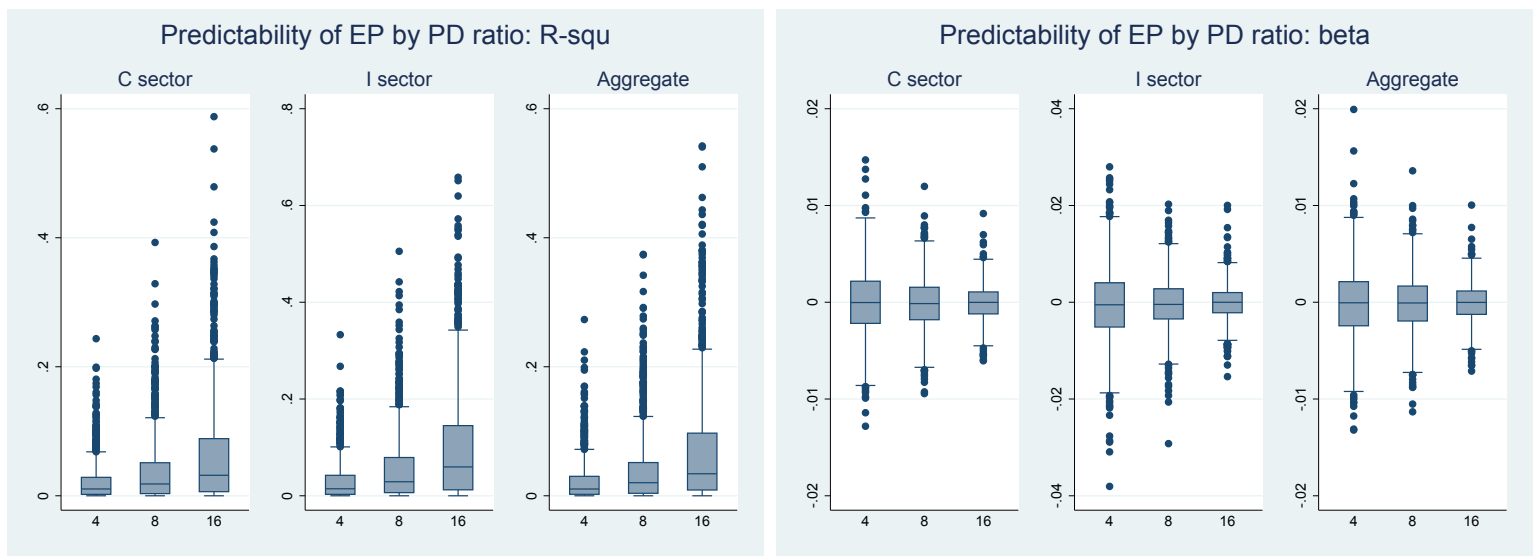

Note: Based on 1,000 simulation runs with 120 data points each; first row - consumption goods sector, second row - capital goods sector; vertical bounds of boxes - 1st quartile (25th percentile) to 3rd quartile (75th percentile); horizontal line in grey box - median

The right schedule of Figure 4.5 shows the simulated betas. They are, on average, in terms of dimension smaller than the empirical coefficient estimates as reported in Table 2.3. However, they are quite dispersed. Considering the fact that the standard deviation throughout ranges between 0.18 and 0.79 percent, the distributions all cover the empirical coefficient point estimates of Table 2.3. Additionally, in line with empirical estimates, for the simulated series the relationship between forwardly projected EPs and the log price-dividend ratios is -as indicated by, though small, throughout negative mean and median figures- negative across horizons. Corresponding R-squared statistics clearly and monotonously increase over the considered forecasting horizons (left schedule of Figure 4.5): For the consumption goods sector and the aggregate economy the median figures increase from 0.01 to 0.02 to 0.03 ; for the investment goods sector from 0.01 to 0.03 to 0.06 ; with standard deviations ranging from 0.03 to 0.11 . Again, 
they are quite in line with the corresponding measures of the empirical point estimates.

In sum, the model seems to pass the litmus test of generating time variation in sectoral risk premia, as measured by regressions of excess returns on the price-dividend ratios. There are clear indications for excess returns being predictable by the log price-dividend ratio.

\subsection{Behavior of the risk-free rate and equity returns in the model}

As we will see in the following, the risk-free rate and the equity returns generated by the model are also slightly predictable by the respectively simulated log price-dividend ratio series across sectors and for the aggregate.

Figure 4.6: Predicting RFR and ER by log price dividend ratios: model
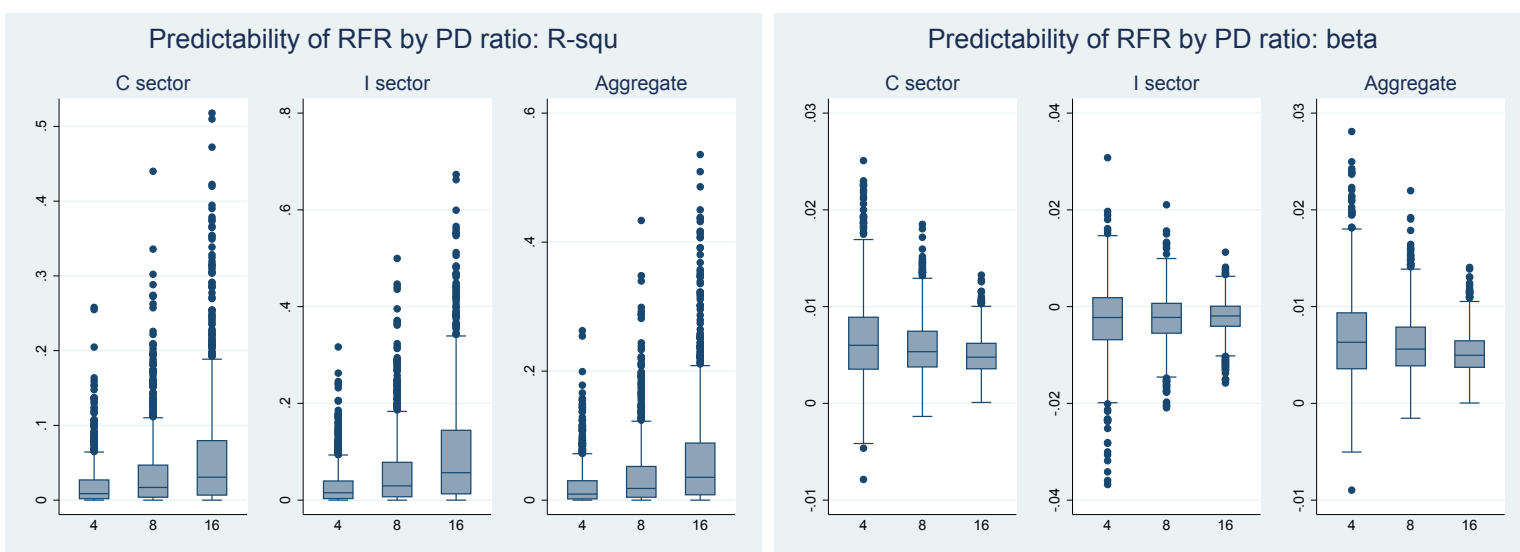

Predictability of ER by PD ratio: R-squ

Predictability of ER by PD ratio: beta
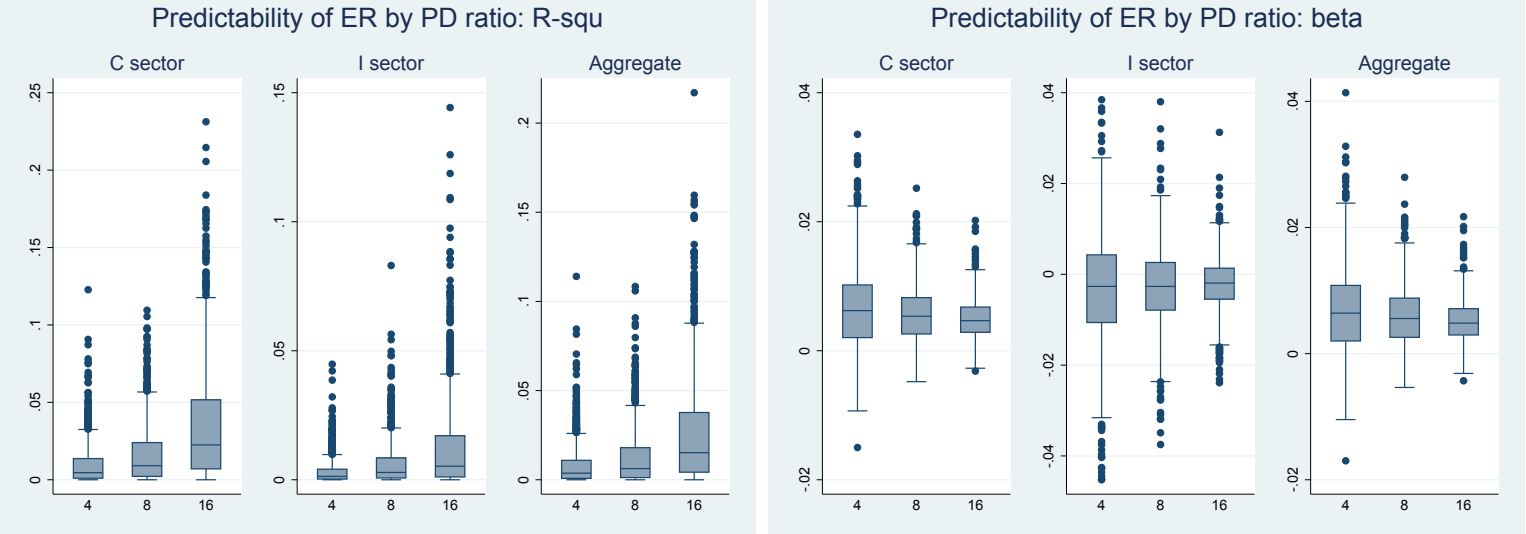

Note: Based on 1,000 simulation runs with 120 data points each; first row - consumption goods sector, second row - capital goods sector; vertical bounds of boxes - 1st quartile (25th percentile) to 3rd quartile (75th percentile); horizontal line in grey box - median 
As displayed in Figure 4.6, the respective simulated log price-dividend ratio also seems to forecast the simulated RFR to some extent (at least, we cannot reject this hypothesis on the base of moments of the shown distributions). It does so somewhat less for the consumption goods sector and the aggregate as can be seen from the R-squared statistics reported in the upper left schedules of Figure 4.6. For equity returns the medians of coefficient estimates are larger than for the empirical counterparts (Table 2.5). Throughout, it seems that -as in the case of equity premia- predictability regression results for the consumption goods sector and the aggregate coincide relatively more than for the investment goods sectors and the aggregate. The picture for the ER series predictability is quite similar to the one for the RFR series. Obviously, we can hardly state a qualitiative difference eyeballing the distributions in the two rows of Figure 4.6.

As can be seen from Table 4.2, we match the volatility of real returns of stocks in the two sectors quite well. On the other hand, we clearly overestimate the volatility of the real risk-free rate in our simulations. In his study of the low-variance-puzzle of the risk-free rate, Allais (2004) succeeds in generating a second moment of equity returns in his model that exceeds the risk-free rate variance by a factor of about 16 . In our case, this factor also exceeds unity but it is obviously smaller amounting to about $1.5{ }^{13}$

Table 4.2

Standard deviations of quarterly real returns 1980:Q1-2009:Q4

\begin{tabular}{lrr}
\hline \multicolumn{1}{c}{ Asset } & U.S. economy & \multicolumn{1}{c}{ Model } \\
\hline Risk-free bond & 0.537 & 8.192 \\
Capital sector stocks & 9.860 & 12.315 \\
Consumption sector stocks & 9.804 & 11.995 \\
\hline
\end{tabular}

Notes: All results are in percent per quarter.

As a possible solution, Gourio (2012) provides a tractable business cycle model that is able to match the low volatility of the short-term interest rate. He introduces a timevariable disaster risk in line with Barro (2006) into the one-sector benchmark model of Jermann (1998). With a very small probability a large macroeconomic shock destroys

\footnotetext{
${ }^{13}$ Unlike our model, Allais (2004) also considers local substitution in addition to habit persistence in the specification of household preferences. Local substitution is modeled in a way such that new consumption expenditures provide a flow of consumption services over time that depreciate at a constant rate. However, Allais (2004) only considers an exchange economy as in Lucas (1978) where dividends (as the only income source) are exogenous and governed by a first-order Markov process. In addition, our production based economy provides an improvement with respect to the modeling of the risk-free rate if compared to the pure habit model of Allais (2004) where the annual variance of the risk-free rate is equal to 13.4 percent.
} 
part of the capital stock and contracts the total factor productivity. In addition, government bonds also default with a strictly positive probability during disasters. As a consequence, the risk-free rate and the short-term interest rate behave differently both in times of a disaster and after a shock that increases disaster probability. In order to match both the high volatility of equity returns and low volatility of the short-term interest rate, however, Gourio relies on the incorporation of leverage (equal to 50\%) into his model. As we have pointed out above, the friction in the allocation of labor in our model introduces sufficient return volatility to match the equity premia in the data. Yet, since our model does not distinguish between an empirically unobserved risk-free rate and government bonds with small default probability, we are unable to match the volatility of the return to treasury bonds found in our data.

\section{Conclusion}

Our research is motivated by previous findings of Greenwood, Hercowitz, and Krusell (1997, 2000), Fisher (2002), and Marquis and Trehan (2005). From data on the relative price of investment goods they infer different trends and short run fluctuations of the productivity in the production of investment goods relative to consumption goods. Their results support the view that it is justified and warranted to distinguish between a consumption goods and a capital goods sector. As a consequence, asset prices in these two sectors are likely to behave differently.

In this paper, we have presented empirical evidence for the return to equity in the consumption goods and capital goods sector. While close to each other, both the equity premium and the Sharpe value are moderately higher in the investment goods sector. The returns in both sectors are contemporaneously uncorrelated with output growth, but significantly positively correlated at a lead of one quarter. In addition, we have constructed a data set to provide new evidence that sectoral equity returns are predictable by sectoral log-price dividend ratios. In order to account for these observations, we have presented a parsimonious two-sector model based on Boldrin, Christiano, and Fisher (2001). In line with Greenwood, Hercowitz, and Krusell (2000) the model features different sectoral growth rates which we estimate from the data set of Fernald (2014). Sector-specific adjustment costs of capital and a modest Frisch elasticity of labor supply are further departures from Boldrin, Christiano, and Fisher (2001). Sector-specific shocks trigger fluctuations around the model's balanced growth path and are propagated by frictions in the allocation of labor and capital. 
In accordance with the empirical evidence, the model predicts a slightly higher equity premia in the investment goods sector than in the consumption goods sector. As in the U.S. data, this difference is not statistically significant. The model is also consistent with our stylized empirical fact that sectoral log price-dividend ratios forecast sectoral equity returns. While we are able to duplicate the correlation pattern of sectoral equity returns with output growth, the lead-lag structure is somehow compressed. Accordingly, our two-sector model is consistent with a significant number of sectoral asset price statistics.

In our strategy to match asset prices and quantitative business cycle effects, we have not relied on the introduction of leveraged returns. Leverage is often introduced into models of a production economy in order to generate sufficient volatility of the return on equity like, for example, in Gourio (2012). Without leverage, the volatility of the returns is basically equivalent to the volatility of the dividend and, hence, output and, for this reason, it is much lower than observed empirically. ${ }^{14}$ We conjecture that the introduction of leverage into our model would even improve the matching of the business cycle statistics. In particular, higher leverage would allow for both smaller capital adjustment costs and more labor mobility in our model so that the volatilities of investment, labor, and, hence, output increase and are closer to their empirical values.

\footnotetext{
${ }^{14}$ In most models like Abel (1999) or Gourio (2012), leverage is introduced in a form that the cash flow process is altered, but the Modigliani and Miller theorem continues to hold such that the business cycle properties of all quantities are unaffected. As one exception, Gourio (2013) also introduces endogenous leverage which also changes business cycle effects and, in particular, allows for a higher volatility of investment.
} 


\section{References}

Abel, A.B., 1999, Risk Premia and Term Premia in General Equilibrium, Journal of Monetary Economics, vol. 43, 3-33.

Albuquerque, R., M.S. Eichenbaum, and S. Rebelo, 2012, Valuation Risk and Asset Pricing, National Bureau of Economics Research (NBER) Working Paper, No. 18617.

Allais, O., 2004, Local Substitution and Habit Persistence: Matching the Moments of the Equity Premium and the Risk-free Rate, Review of Economic Dynamics, vol. 7, 265-296.

Andreasen, M.M., 2012, On the Effects of Rare Disasters and Uncertainty Shocks for Risk Premia in Non-Linear DSGE Models, Review of Economic Dynamics, vol. 15, 295-316.

Backus, D.K., B.R. Routledge, and S.E. Zin, 2007, Asset Prices in Business Cycle Analysis, Carnegie Mellon University Working Paper, No. 11-20-2007.

Blanchard, O.J., and J. Galí, 2007, Real Wage Rigidities and the New Keynesian Model, Journal of Money, Credit, and Banking, Supplement to vol. 39(1), 35-65.

Boldrin, M., L.J. Christiano, and J.D.M. Fisher, 2001, Habit Persistence, Asset Return, and the Business Cycle, American Economic Review, vol. 91, 149-166.

Campbell, J.Y., 2003, Consumption-based Asset Pricing, in: Constantinides, G.M., M. Harris, and R. Stulz, Handbook of the Economics of Finance, Amsterdam: Elsevier, 801-871.

Christiano, L.J., M. Eichenbaum, and Ch.L. Evans, 2005, Nominal Rigidities and the Dynamic Effects of a Shock to Monetary Policy, Journal of Political Economy, vol. 113, 1-45.

Cooley, Th.F. and E.C. Prescott, 1995, Economic Growth and Business Cycles, in: Th. F. Cooley (Ed.), Frontiers of Business Cycle Research, Princeton, NJ: Princeton University Press, 1-38.

Covas, F. and W. Den Haan, 2012, The Role of Debt and Equity Finance over the Business Cycle, Economic Journal, vol. 122(565), 1262-1286.

Fernald, J., 2014, A Quarterly, Utilization-Adjusted Series on Total Factor Productivity, Federal Reserve Bank of San Fransisco Working Paper No. 2012-19.

Fisher, J.D.M., 2002, Technology Shocks Matter, Federal Reserve Bank of Chicago Working Paper No. 2002-14.

Gourio, F., 2012, Disaster Risk and Business Cycles, American Economic Review, vol. 102, 2734-2766. 
Gourio, F., 2013, Credit Risk and Disaster Risk, American Economic Journal: Macroeconomics, vol. 5, 1-34.

Greenwood, J., Z. Hercowitz, and P. Krusell, 1997, Long-Run Implications of InvestmentSpecific Technological Change, American Economic Review, vol. 87, 342-362.

Greenwood, J., Z. Hercowitz, and P. Krusell, 2000, The Role of Investment-Specific Technological Change in the Business Cycle, European Economic Review, vol. 44, 91-115.

Hansen, G.D., 1985, Indivisible Labor and the Business Cycle, Journal of Monetary Economics, vol. 16, 309-327.

Heer, B., and A. Maußner, 2009, Dynamic General Equilibrium Models: Computation and Applications, 2nd edition, Heidelberg: Springer.

Heer, B., and A. Maußner, 2013, Asset Returns, the Business Cycle, and the Labor Market, German Economic Review, vol. 14(3), 2013, 372-397.

Heer, B., A. Maußner, and B. Süssmuth, 2013, Cyclical Asset Returns in the Consumption and Investment Goods Sector, CESifo Working Paper Series No. 4364.

Ireland, P., and S. Schuh, 2008, Productivity and U.S. Macroeconomic Performance: Interpreting the Past and Predicting the Future with a Two-Sector Real Business Cycle Model, Review of Economic Dynamics, vol. 11(3), 473-492.

Jagannathan, R., E.R. McGrattan, and A. Scherbina, 2000, The declining U.S. equity premium, Quarterly Review, Federal Reserve Bank of Minneapolis, Fall, 3-19.

Jermann, U.J., 1998, Asset Pricing in Production Economies, Journal of Monetary Economics, vol. 41, 257-275.

Kocherlakota, N.R., 1996, The Equity Premium: It's Still a Puzzle, Journal of Economic Literature, vol. XXXIV, 42-71.

Lucas, R., 1978, Asset Prices in Exchange Economies, Econometrica, vol. 46, 14261446 .

Marquis, M., and B. Trehan, 2005, On Using Relative Prices to Measure CapitalSpecific Technological Progress, Journal of Macroeconomics, vol. 30(4), 13901406.

Mehra, R., and E.C. Prescott, 1985, The Equity Premium: A Puzzle, Journal of Monetary Economics, vol. 15. 145-161.

Newey, W. and K. West, 1987, A simple positive semi-definite, heteroskedasticity and autocorrelation consistent covariance matrix, Econometrica 55, 703-708.

Papanikolaou, D., 2011, Investment Shocks and Asset Prices, Journal of Political Economy, vol. 119(4), 639-685. 
Uhlig, H., 2007, Explaining Asset Prices with External Habits and Wage Rigidities in a DSGE Model, American Economic Review, Papers $\mathcal{E}$ Proceedings, vol. 97, 239-243. 


\section{Appendix}

\section{A.1 Dynamics of the model}

The dynamics of the model presented in Section 3 is determined by equations (3.1), (3.3), (3.10), (3.12), (3.13a), (3.16a), (3.15) as well as the tfp processes (3.2) and (3.4). In addition, equations (3.5) and (3.6) define GDP in current prices and aggregate hours and aggregate capital. For convenience, we summarize this set of equations and add an equation for the aggregate real wage (A.1i) and aggregate investment (A.1k):

$$
\begin{aligned}
C_{t} & =Z_{C t} N_{C t}^{1-\alpha} K_{C t}^{\alpha} \\
I_{t} & =Z_{I t} N_{I t}^{1-\alpha} K_{I t}^{\alpha} \\
w_{C t} & =(1-\alpha) \frac{C_{t}}{N_{C t}} \\
w_{I t} & =(1-\alpha) p_{t} \frac{I_{t}}{N_{I t}} \\
q_{C t} & =\frac{p_{t}}{\Phi^{\prime}\left(I_{C t} / K_{C t}\right)} \\
q_{I t} & =\frac{p_{t}}{\Phi^{\prime}\left(I_{I t} / K_{I t}\right)}, \\
N_{t} & =N_{C t}+N_{I t} \\
K_{t} & =K_{C t}+K_{I t}, \\
w_{t} & =\frac{N_{C t}}{N_{t}} w_{C t}+\frac{N_{I t}}{N_{t}} w_{I t}, \\
Y_{t} & =C_{t}+p_{t} I_{t}, \\
I_{t} & =I_{C t}+I_{I t}, \\
\Lambda_{t} & =\left(C_{t}-\chi C_{t-1}\right)^{-\eta}-\beta \chi \mathbb{E}_{t}\left(C_{t+1}-\chi C_{t}\right)^{-\eta}, \\
0 & =\mathbb{E}_{t}\left[\nu_{0} N_{t+1}^{\nu_{1}}-\Lambda_{t+1} w_{C t+1}\right] \\
0 & =\mathbb{E}_{t}\left[\nu_{0} N_{t+1}^{\nu_{1}}-\Lambda_{t+1} w_{I t+1}\right] \\
q_{C t} & =\beta \mathbb{E}_{t} \frac{\Lambda_{t+1}}{\Lambda_{t}}\left\{\alpha \frac{C_{t+1}}{K_{C t+1}}-\frac{p_{t+1} I_{C t+1}}{K_{C t+1}}+q_{C t+1}\left[\left(\Phi\left(I_{C t+1} / K_{C t+1}\right)+1-\delta\right]\right.\right. \\
K_{I t+1} & =\Phi\left(I_{I t} / K_{I t}\right) K_{I t}+(1-\delta) K_{I t} . \\
q_{I t} & =\beta \mathbb{E}_{t} \frac{\Lambda_{t+1}}{\Lambda_{t}}\left\{p_{t+1} \alpha \frac{I_{t+1}}{K_{I t+1}}-\frac{p_{t+1} I_{I t+1}}{K_{I t+1}}+q_{I t+1}\left[\left(\Phi\left(I_{I t+1} / K_{I t+1}\right)+1-\delta\right]\right\}\right.
\end{aligned}
$$




\section{A.2 Balanced growth path}

With different rates of technological progress, $a_{C} \neq a_{I}$ not all variables will grow at the same rate on a balanced growth path. The definition of GDP in current prices given in equation (A.1j) implies that GDP and consumption will grow at the same rate $g_{Y}=g_{C}$ which in turn will have to satisfy

$$
\left(1+g_{Y}\right)=\left(1+g_{p}\right)\left(1+g_{I}\right),
$$

where $g_{p}$ and $g_{I}$ denote the growth rate of the relative price of investment goods and aggregate investment, respectively. The equations for capital accumulation, (A.1q) and (A.1r), imply that both stocks of capital will grow at the rate at which investment in both sectors grows so that $g_{K}=g_{I}$. As a consequence, the production function for investment goods

$$
I_{t}=Z_{I t} N_{I t}^{1-\alpha} K_{I t}^{\alpha}
$$

yields

$$
\left(1+g_{K}\right)=\left(e^{a_{I}}\right)^{\frac{1}{1-\alpha}} .
$$

Analogously, the production function for consumption goods implies

$$
\left(1+g_{C}\right)=\left(e^{a_{C}}\right)\left(1+g_{K}\right)^{\alpha} .
$$

Taken together, (A.3) and (A.4) determine the growth rate of consumption and output:

$$
\left(1+g_{C}\right)=\left(e^{a_{C}}\right)\left(e^{a_{I}}\right)^{\frac{\alpha}{1-\alpha}} .
$$

Using this result in (A.2) delivers the rate of change of the relative price of investment goods:

$$
\left(1+g_{p}\right)=e^{a_{C}-a_{I}} .
$$

\section{A.3 The model in stationary variables}

In order to solve and simulate the model we must formulate it in stationary variables, i.e., in variables that are defined relative to their respective growth path. Towards this purpose we define

$$
Z_{t}=Z_{C t} Z_{I t}^{\frac{\alpha}{1-\alpha}}
$$

and construct the scaled variables

$$
z_{t}=\frac{Z_{t}}{Z_{t-1}},
$$




$$
\begin{aligned}
x_{t} & =\frac{X_{t}}{Z_{t-1}} \text { for } X \in\{Y, C\}, \\
x_{t} & =\frac{Y_{t}}{Z_{I t-1}^{\frac{1}{1-\alpha}}} \text { for } X \in\left\{I, I_{C}, I_{I}, K, K_{C}, K_{I}\right\}, \\
\lambda_{t} & =\Lambda_{t} A_{t-1}, \\
z_{X t} & =\frac{Z_{X t}}{Z_{X t-1}}=e^{a_{X}+\sigma_{X} \epsilon_{t}} \text { for } X \in\{C, I\}, \\
\tilde{q}_{X t} & =q_{X t} \frac{Z_{I t-1}}{Z_{C t-1}} \text { for } X \in\{C, I\}, \\
\tilde{p}_{t} & =p_{t} \frac{Z_{I t-1}}{Z_{C t-1}}, \\
\tilde{w}_{X t} & =\frac{w_{X t}}{Z_{t-1}} \text { for } X \in\{C, I\} .
\end{aligned}
$$

With these definitions equations (A.1) turn into:

$$
\begin{aligned}
c_{t} & =z_{C t} N_{C t}^{1-\alpha} k_{C t}^{\alpha}, \\
i_{t} & =z_{I t} N_{I t}^{1-\alpha} k_{I t}^{\alpha}, \\
\tilde{w}_{C t} & =(1-\alpha) \frac{c_{t}}{N_{C t}}, \\
\tilde{w}_{I t} & =(1-\alpha) \tilde{p}_{t} \frac{i_{t}}{N_{I t}}, \\
\tilde{q}_{C t} & =\frac{\tilde{p}_{t}}{\Phi_{C}^{\prime}\left(i_{C t} / k_{C t}\right)}, \\
\tilde{q}_{I t} & =\frac{\tilde{p}_{t}}{\Phi_{I}^{\prime}\left(i_{I t} / k_{I t}\right)}, \\
N_{t} & =N_{C t}+N_{I t}, \\
k_{t} & =k_{C t}+k_{I t}, \\
\tilde{w}_{t} & =\frac{N_{C t}}{N_{t}} \tilde{w}_{C t}+\frac{N_{I t}}{N_{t}} \tilde{w}_{I t}, \\
y_{t} & =c_{t}+\tilde{p}_{t} i_{t}, \\
i_{t} & =i_{C t}+i_{I t}, \\
\lambda_{t} & =\frac{(\mathrm{A} .9 \mathrm{a})}{c_{t}-\chi\left(c_{t-1} / z_{t-1}\right)}-\mathbb{E}_{t} \frac{\beta \mathrm{b})}{z_{t} c_{t+1}-\chi c_{t}}, \\
0 & =\mathbb{E}_{t}\left[\nu_{0} N_{t+1}^{\nu_{1}}-\lambda_{t+1} \tilde{w}_{C t+1}\right], \\
0 & =\mathbb{E}_{t}\left[\nu_{0} N_{t+1}^{\nu_{1}}-\lambda_{t+1} \tilde{w}_{I t+1}\right], \\
\tilde{q}_{C t} \lambda_{t} & =\beta z_{I t-1}^{\frac{-1}{1-\alpha}} \mathbb{E}_{t} \lambda_{t+1}\left\{\alpha \frac{c_{t+1}}{k_{C t+1}}-\tilde{p}_{t+1} \frac{i_{C t+1}}{k_{C t+1}}+\tilde{q}_{C t+1}\left[\Phi_{C}\left(i_{C t+1} / k_{C t+1}\right)+1-\delta\right]\right\}
\end{aligned}
$$




$$
\begin{aligned}
\tilde{q}_{I t} \lambda_{t} & =\beta z_{I t-1}^{\frac{-1}{1-\alpha}} \mathbb{E}_{t} \lambda_{t+1}\left\{\alpha \tilde{p}_{t+1} \frac{i_{t+1}}{k_{I t+1}}-\tilde{p}_{t+1} \frac{i_{I t+1}}{k_{I t+1}}+\tilde{q}_{I t+1}\left[\Phi_{I}\left(i_{I t+1} / k_{I t+1}\right)+1-\delta\right]\right\} \\
z_{I t}^{\frac{1}{1-\alpha}} k_{C t+1} & =(1-\delta) k_{C t}+\Phi_{C}\left(i_{C t} / k_{C t}\right), \\
z_{I t}^{\frac{1}{1-\alpha}} k_{I t+1} & =(1-\delta) k_{I t}+\Phi_{I}\left(i_{I t} / k_{I t}\right) .
\end{aligned}
$$

\section{A.4 Stationary solution}

The stationary solution derives from the system of equations (A.9) if we ignore the two shocks (and, thus, the expectations operator) and assume that the economy has settled on its balanced growth path: $y_{t+1}=y_{t}=y$ for all variables $y$ of the model.

The stationary solution is free of adjustment costs, i.e., for $X \in\{C, I\}$ :

$$
\begin{aligned}
\Phi_{X}^{\prime}\left(i_{X} / k_{X}\right) & =1, \\
\Phi_{X}\left(i_{X} / k_{X}\right) & =z_{I}^{\frac{1}{1-\alpha}}+1-\delta, \\
z_{I} & =e^{a_{I}} .
\end{aligned}
$$

Therefore, from equations (A.9e) and (A.9f)

$$
\tilde{q}_{C}=\tilde{q}_{I}=\tilde{p}
$$

and from equations (A.9q), (A.9r), (A.9k), and (A.9h)

$$
\begin{aligned}
i_{C} & =\left(z_{I}^{\frac{1}{1-\alpha}}+1-\delta\right) k_{C}, \\
i_{I} & =\left(z_{I}^{\frac{1}{1-\alpha}}+1-\delta\right) k_{I}, \\
i & =\left(z_{I}^{\frac{1}{1-\alpha}}+1-\delta\right) k .
\end{aligned}
$$

Equations $(\mathrm{A} .9 \mathrm{~m})$ and $(\mathrm{A} .9 \mathrm{n})$ imply $\tilde{w}_{C}=\tilde{w}_{I}$ so that $(\mathrm{A} .9 \mathrm{c})$ and $(\mathrm{A} .9 \mathrm{~d})$ deliver

$$
\tilde{p}=\frac{z_{C}}{z_{I}}\left(\frac{k_{c} / N_{c}}{k_{I} / N_{I}}\right)^{\alpha} .
$$

Equations (A.9o) and (A.9p) imply

$$
\frac{k_{C}}{k_{I}}=\frac{1}{\tilde{p}} \frac{c}{i},
$$


which together with (A.9a) and (A.9b) delivers

$$
\frac{k_{C}}{k_{I}}=\frac{1}{\tilde{p}} \frac{z_{C}}{z_{I}} \frac{N_{C}^{1-\alpha} k_{C}^{\alpha}}{N_{I}^{1-\alpha} k_{I}^{\alpha}} .
$$

Combing this result with equation (A.10e) implies

$$
\begin{aligned}
\frac{k_{c}}{N_{C}} & =\frac{k_{I}}{N_{I}}=\frac{k}{N}, \\
\tilde{p} & =\frac{z_{C}}{z_{I}} .
\end{aligned}
$$

Given these results $k_{C} / N_{C}$ can be determined from the stationary version of equation (A.9o):

$$
\frac{k_{C}}{N_{C}}=\frac{k}{N}=\left[\frac{z_{I}^{\frac{1}{1-\alpha}}-\beta(1-\delta)}{\alpha \beta z_{I}}\right]^{\frac{1}{\alpha-1}}
$$

For given $N$ this equation determines $k$ so that $i$ follows from

$$
i=\left(z_{I}^{\frac{1}{1-\alpha}}-1+\delta\right) k .
$$

Via the production function for investment goods, (A.9i), we can back out hours spent working in the investment sector:

$$
N_{I}=\frac{i}{z_{I}}(k / N)^{-\alpha} .
$$

Given this solution we can work backwards to compute the remaining variables. 